\title{
جماليات الصبر في قصيدة(أرى الصبر محمودا) لابن الرومي ( دراسة تحليلية في الدلالات والأساليب)
}

\author{
نور بنت عويض الرفاعي \\ أستاذ مشارك - قسم اللغة العربية \\ كلية اللغات والترجمة- جامعة جدة
}

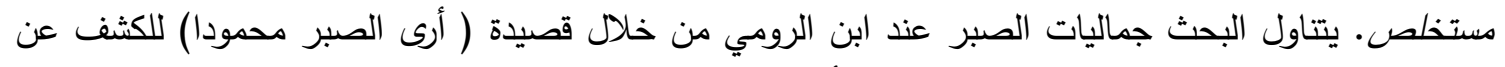

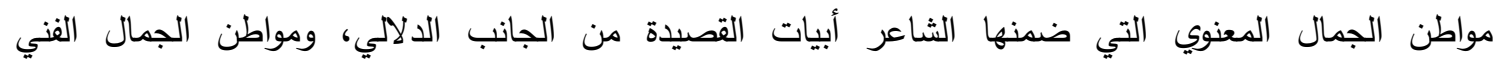

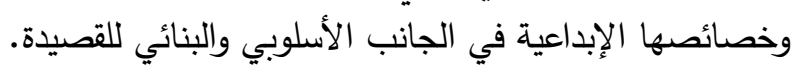

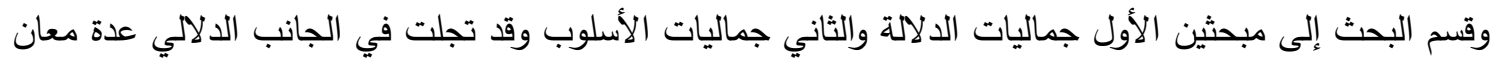

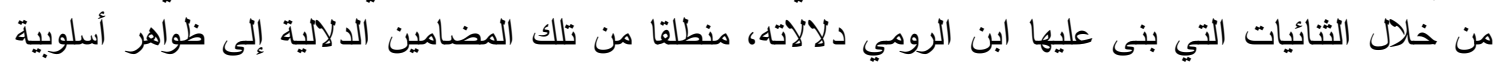

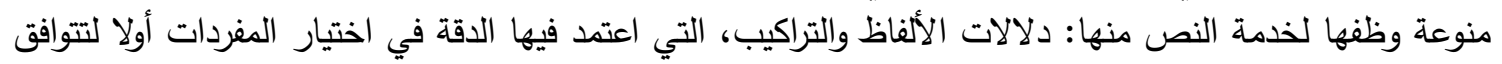

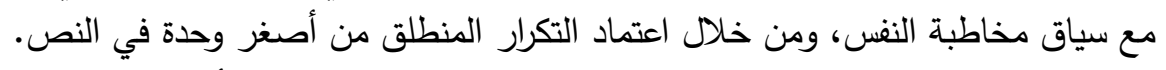

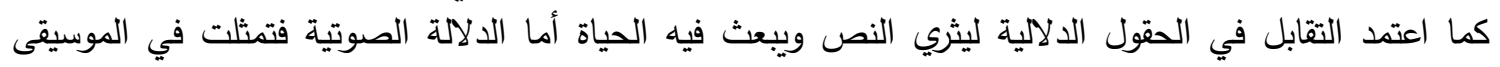

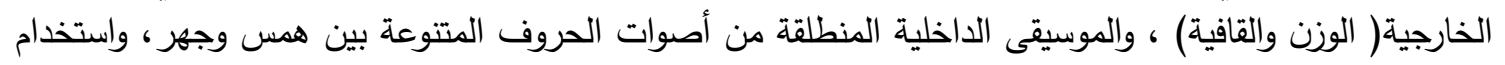
فنون علم البديع اللفظية والمعنوية. وجاء المبحث الثاني في جماليات الأساليب متناولا الأساليب التركيبية الخبرية والإنشائية والتكرار ثم الأساليب التصويرية التي كثفت عن الصناء في الصور الفنية في القصيدة. الكلمات المفتاحية: جماليات، الصبر ، ابن الرومي، الصئ الدلالات، الأساليب

سئمتُ تكاليفَ الحياةِ ومنْ يعشْثمانينَ حولا لا أبا لك

\section{المقدِمة}

يسأُم' .

وقول المتنبيّ:على قدرِ أهلِ العزم تأتي العزائُ وتأتي على قدرِ الكرامِ المكارُّ.

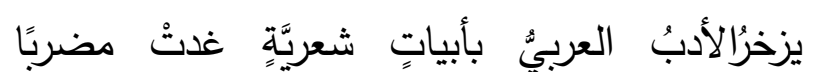

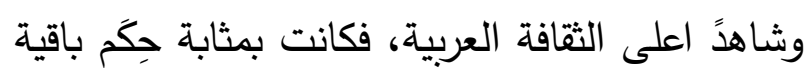
على مرّ الزمان، نحو قول زهير بن أبي سُلمى:

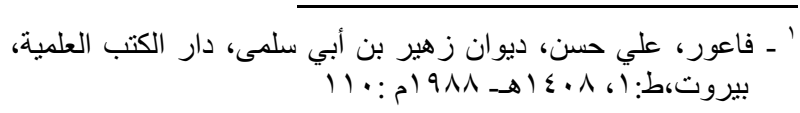


وابن الرومي شاعر كبير قدأغفله بعض النقاد القدماء

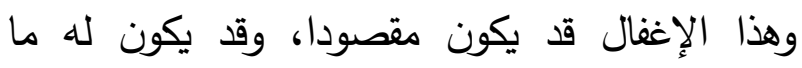

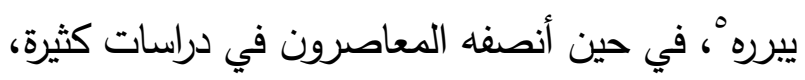

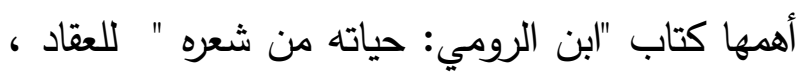

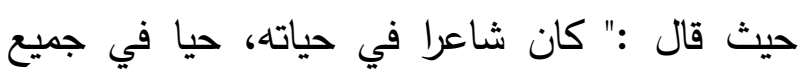
شعره، وإن الشعرَ كان لأناس غيره كساء عيدٍ أو حلةَ هئَ

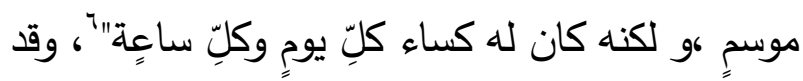
نشأ وترعرع في بغداد، وتعلَّم العلم عن علمِ علمِ وكائها، نظم

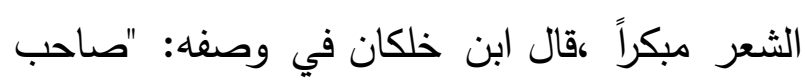
النظم العجيب والتوليد الغريب، يغوص على المعاني النادرة فيستخرجها من مكانها، ويبرزها في أحسن صورة، ولا يترك المعنى حتى يستوفيه إلى أخره ولا يبقي فيه بقية." وقد تعرض على مدار حياته للكثير من الكوارث

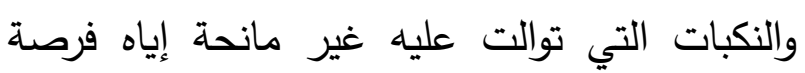
للتفاؤل، وقد تركت آثارها عليه، حيث جاءت أثبات أشعاره

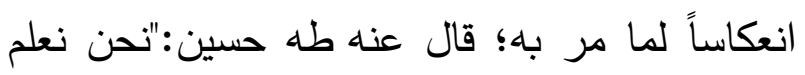
أنه كان سيء الحظ في حياته، ولم يكن محبباً إلى لى فئه الناس، وإنما كان مبغضاً إليهم، وكان مُحسداً أيضاً،

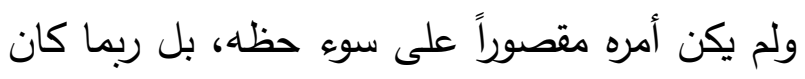

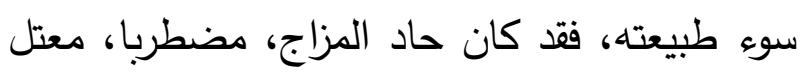
الطبع، ضعيف الأعصاب، حاد الحسّ جدَّا، يكاد

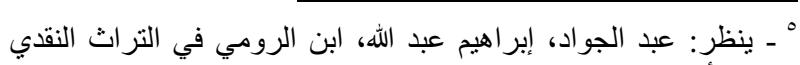

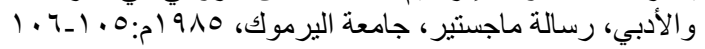

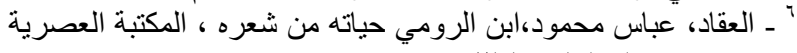

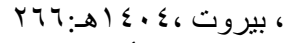

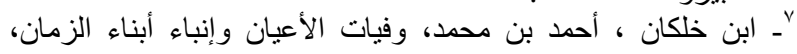

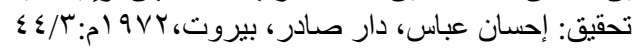

وكذلك قول ابن الرومي:أرى الصبَر محموداً وعنه

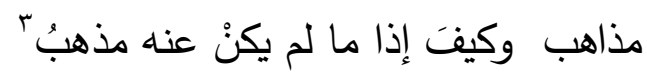

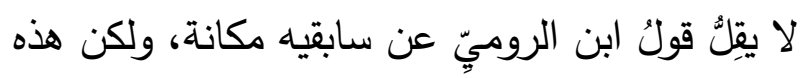

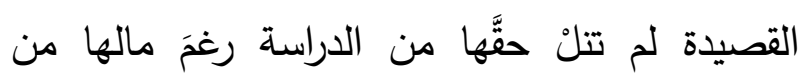

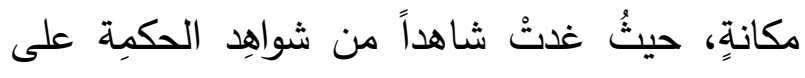

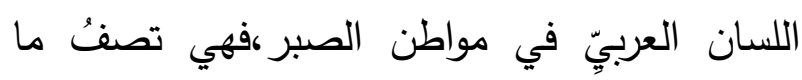
للصبر من فضائل. خاسُر من لم يحصدها، ويتحلَّ

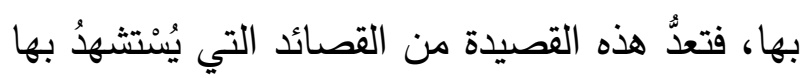

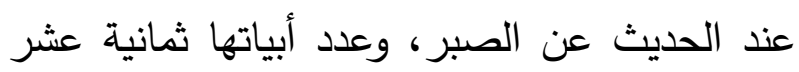
بيتًا، لم يرد لها شرحا سوى لبعض مفرداتها في

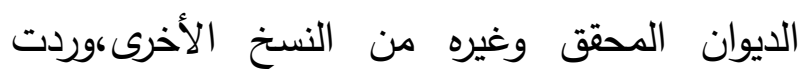
بعض أبياتها عند الشوكانيّ في كتابه فتح القدير: "أن الصابر على ما نزل به قد فاز بهذا الأجر

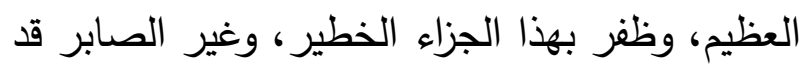

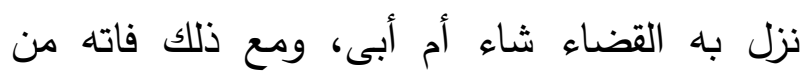

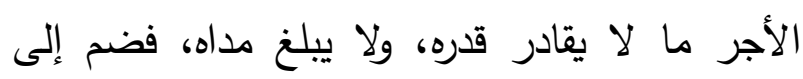
مصيبته دصيبة أخرى، ولم يظغر بغير الجزع، وما أحسن قول من قال:

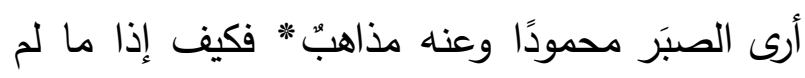
يكن عنه مذهبُ

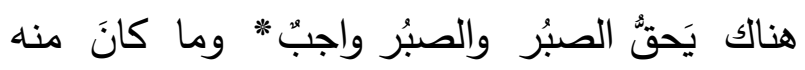

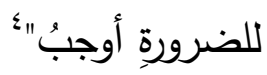

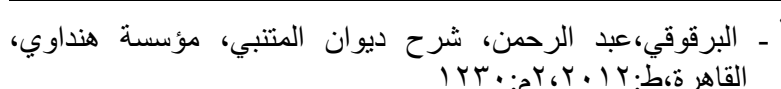

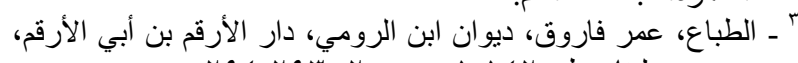

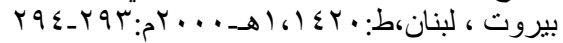

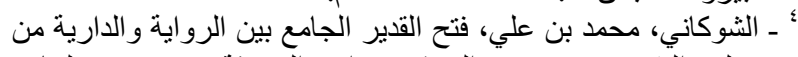

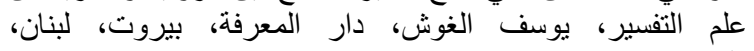
ط:م 
التي تعد من جواهر الأدب في مضمونها وخصائص خطابها الأدبيّ ، فالجمال " جزء أصيل له أهمية في العملية الإبداعية من خلال الموقف الجماليّ، وموقف الفنان أثناء حالات الاستجابة من خلال وعي جمالي للمدركات الحالية قبل وأثناء وبعد العملية الإبداعية "'، فجاءت الدراسة في مبحثين:

المبحث الأول: جماليات الالالة

يتناول هذا المبحث الألفاظ وما تؤديه من دلالات إيحائية وصوتية، إضافة للظواهر الدلالية التي كان لها دور في بناء القصيدة . المبحث الثاني : جماليات الأساليب يركز هذا المبحث على طرائق التعبير التي اعتمدها الثاعر في التعبير عن مدلولات النص على اختلافها تركيبا وتصويرا. وسيكون عملنا عرض وتحليل ما في القصيدة من جماليات، فدراسة قصيدة (أرى الصبر) تسعى إلى بيان القيم التعبيرية والجمالية، فآثرت تحليلها للكشف عن جمالياتها، وتسليط الضوء على ما يحمله فكر ابن الرومي من تجربة وفهم عميق لأحوال الدنيا؛ لأنه لم ينل من الحظوة الأدبية ما ناله غيره من الشعراء.

اتبعت الدراسة المنهج الوصفي القائم على التحليل للغة النص مستعينة بما جاءت به الأسلوبية الحديثة من أدوات تحليلية لمستويات اللغويّة للنص،مع الربط بحياة الشاعر ،وهذا التحليل يحاول من جهته

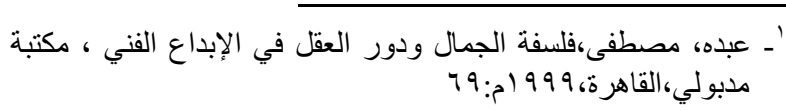

يبلغ من ذلك الإسراف " ^وإذا ألقينا نظرة إلى تاريخ تلك المآسي التي مر بها نجد أنه ورث أملاكا كثيرة عن والده أضاع بعضها بإسرافه ولهوه، أما الجزء الباقي فأهلكته الكوارث ؛إذ احترقت ضيعته، وغُصِبَتْ دارُه، وفَتلكَ الجرادُ بزرعه،، وجاء الموت؛ ليفرط عقد عائلته واحداً تلو الآخر . كان شعر ابن الرومي صورةً عن حياته، وما كان يعانيه في مجتمعه ومن أهل زمانه:إذ نظم ألفين وإحدى و أربعين قصيدة ومقطوعة مابين قصائد مستقلة بغرض واحد، وأخرى قصائد طوال ذات أغراض متعددة . فابن الروميٌّ كان: " ضنينا بالمعاني حريصا عليها، يأخذ المعنى الواحد ويولده، فلا يزال يقلبه ظهرًا لبطن ،ويصرفه في كل وجه وإلى كل ناحية ، حتى يميته كويعلم أنه لا مطمع منه لأحد "ه"، ولعل الصبريات خير ما يمثل ابن الرومي شاعر الأسى والألم . ومن هنا جاءت فكرة دراسة قصيدة ابن الرومي (أرى الصبر) القصيدة التي تحمل بين طياتها الجمال المعنوي الذي يدرك بالبصيرة،و لم تتصف في أدب ابن الرومي وقد ضمنها تجربته ومفهومه للصبر؛ وذلك لغرض الوقوف على أبرز الجماليات التي استلهمها الثاعر في بناء قصيدته، في جانبي: الدلالات والأساليب التي اشتملت عليها هذه القصيدة ^ ـ طه حسين، من حديث الثعر و النثر ،مؤسسة هنداوي للتعليم و الثقافة،

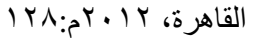
ـ القيرواني الأزدي، الحسن بن رشيق، العن العدة في محاسن الشعر وآدابه

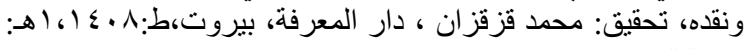
rTh/ 


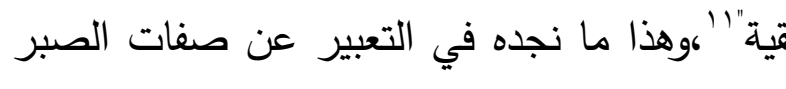
في هذه؛ فقد كان دقيقا في اختيار الدفردات المجاورة (الصبر محمودٌ - الصبر واجبّ- الصبر جميلّ)، فآثر هذه الكلمات دون غيرها لما تؤديه من دلالات معنوية في إظهار محاسن الصبر. ولفظ (محمود) قد جاء في مقاييس اللغة لابن فارس:

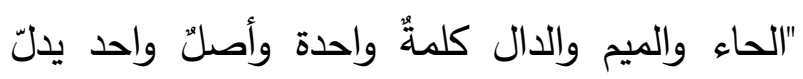
على خلاف الذّمّ .يقال حَمِدْتُ فلاناً أحمَدَده. ورجل محمود ومحمّد، إذا كثُرت خصاله المحمودة غيرُ

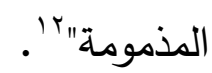
وهذا المعنى مُنطبقِّ على الصبر فهو مددوحٌ، له من الكن الخلال الكثيرة التي لا يغفل عنها عاقلّ، فكيف يُترك؟؟، وفي كلمة (واجب)"اللواو والجيم والباء : أصل

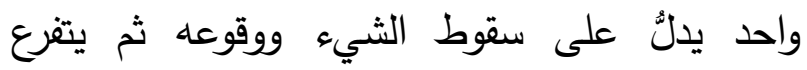

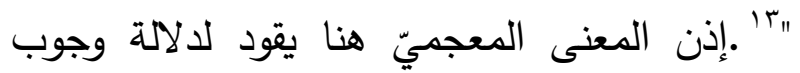
التحلي بالصبر ووقوعه كأمر لازم في حياة الإنسان،

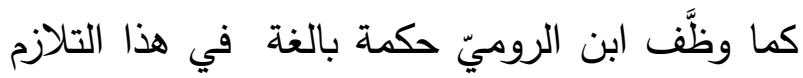
لهذه المفردات يضاف لذلك جملة ( الصبر جميل )،

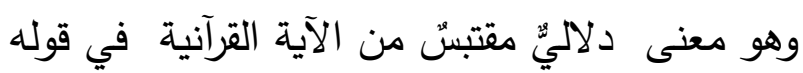

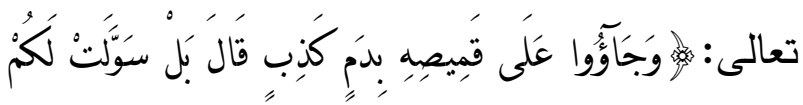

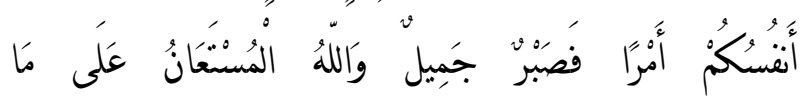

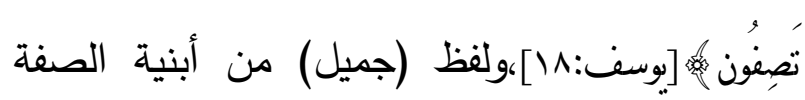

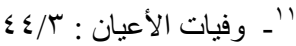

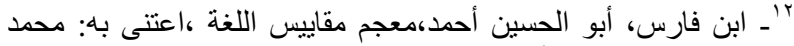
عوض وفاطمة أصلان، دار إحباء التراث العربي، بيروت، التهن،

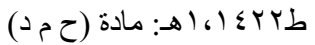
׳" - ينظر المرجع السابق: مادة (و ج ب)
استخراج العناصر الدكونّة للغرض الثعري الذي

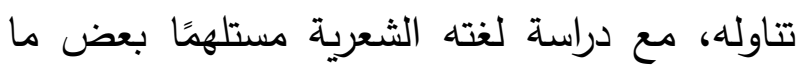
جاءت به المناهج النقدية الحديثة، معتمدة على الفئل

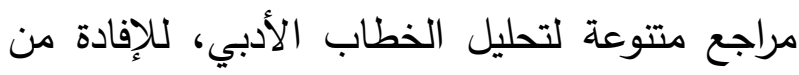

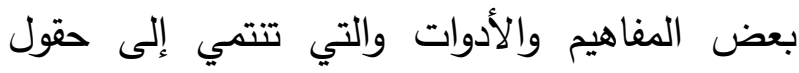
معرفية متعددة، لها دورها في الكثف عن جماليات

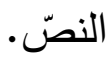
المبحث الأوّل: جماليات الدالة يظهر للمتأمّل ما تزخر بها القصيدة من الظواهر

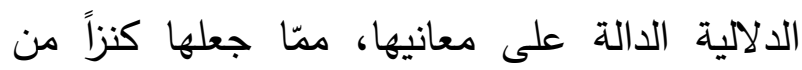
كنوز الحكمة في ذاكرة الثعر العربي، اعتمد فيها ابن الرومي على مخاطبة عقل المتلقي واضعًا له له

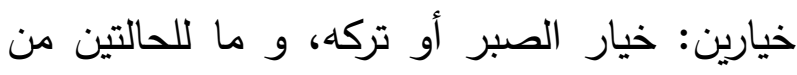

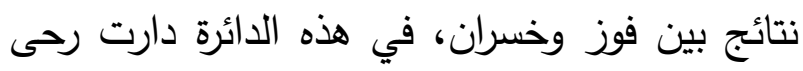
المضامين الدلاليّة لهذه القصيدة، فتتوعت الظواهر فئرة

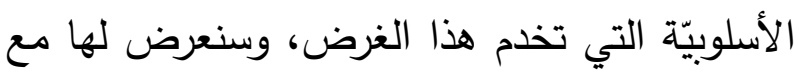
بيان دورها الدلاليّ في تثكيل المنىى وفق العناصر التالية : أولاً: دلالات الألفاظ والتراكيب ثانيًا: الدالة الصوتية - أولاً: دلالات الألفاظ والتراكيب عرَّف ابنُ الرومي، باستقصاء المعاني، وهو الآني قال ابن خلكان في وصفه:" صاحب النظم العجيب الني والتوليد الغريب، يغوصن على المعاني النادرة فيستخرجها من مكانها، ويبرزها في أحسن صورة، ولا لألان يترك المغنى حتى يستوفيه إلى آخره ،ولا ييقي فيه 
حاول الشاعر من خلال خطاب حقل الصبر أن يبعث في النصّ روحًا جديدة تتغَّلب على عادات النفس التي تستثقل الصبر، وتهرب منه، وهذا المضمون هو ما ختم به ابن الرومي قصيدته:

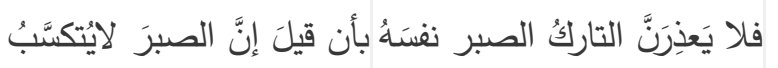
وفي رائعة ابن الرومي اختزالُّ دلالي في مفردة (أرى)

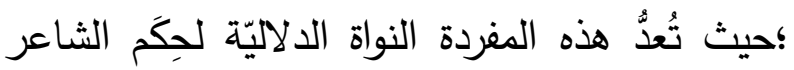
التي حوتها القصيدة، فهي خلاصة تجربة ابن الرومي في مقدمة القصيدة كنتيجة لا تقبل الثك فيما يراه الشاعر حقيقة تجربته

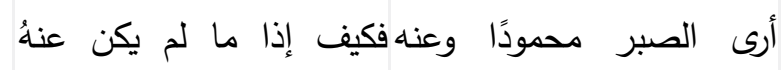

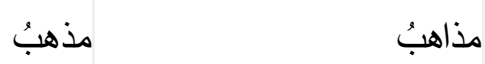

تُظهر اختيارات الثاعر ملكة ابن الروميّ في النفاذ إلى باطن المعنى؛ فهو بعدد محدود من الكلمات ،أو من الأبيات يقف على مضمون الدلاليّ، فكان للمفردة دورها في إظهار مكامن المعاني في القصيدة، كذلك كان لدلالة الظواهر التركيبيّة دور بارز في بناء القصيدة، ونعرض لها على النحو

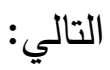
- - - - التَّكرار الدالاليّ دراسةُ التَّكرارِ تحمل في ثناياها دلالات تعبيرية متتوعة تفرضها طبيعة السياق؛ فالتكرار من الأدوات الجمالية التي تساعد على فهم النصّ، إضافة لدوره الجليٌّ في تماسك النصّ ماجاء منه في المفردات أو المعاني،ويعرف الجرجانيّ التكرار في كتابه التعريفات :"عبارة عن الإثبات بشيء مرة بعد
المشبهة ؛إذ اتصفت بالثبوت والدوام ، وهي هنا تدل على دوام وثبوت صفة الجمال في الصبر • جاءت اختيارات الشاعر للمفردات متوافقة مع السياق في مخاطبة النفس التي لا تحتمل الصبر، فحشد الشاعر لذلك ظواهر دلالية ذات بُعْدٍ دلاليّ مشترك يحمل مضمون الجملة الرئيسة في النص (أرى

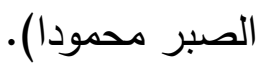
وفي جانب التحليل الدلاليّ الأسلوبيّ نقف عند الحقول الدلاليّة، فقارئ هذه القصيدة يقف بين حقلين دلالين كشفت عنهما الألفاظ التي عقد الثاعر من خلالها مقابلة بين حال الإنسان صابراً وحاله جزوعًا

\begin{tabular}{|c|c|}
\hline حقل الجزع & حقل الصبر \\
\hline 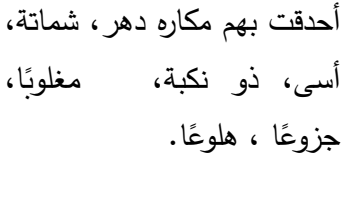 & 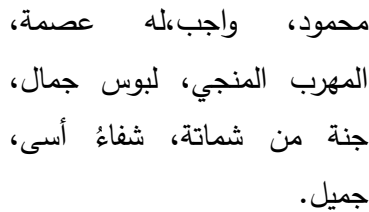 \\
\hline
\end{tabular}

الصبر من أصعب الأمور على النفس الإنسانية، فأراد الشاعر من خلال هذا التقابل الدلاليّ بين الحقلين أن يعقد معركة تدور داخل النفس عندما تهاجمها براثن المكاره، وتثقلها مشقة الصبر وتتنازعها الأحوال المتقلبة في هذه الحياة، فَتَضْحي جزوعًا إن أصابتت مصيبة وتُمسي هلوعاً إن تَعذَّرَ مَطلبُ، فيجعل الخطاب الدلاليّ قارئ النص ذا قرار تصنعه المفردات بما تحمله من إيحاءات؛ فقد خلقت هذه النفس هلوعة كما جاء في قوله تعالى:" إنَّ

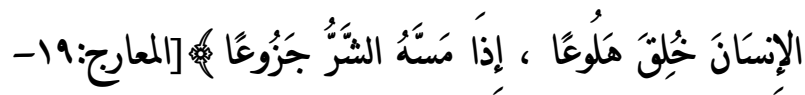


لفائدة، أو هو تأدية المعنى بعبارة زائدة لفائدة تقويته وتوكيده" ('v ) ، فكان وسيلة الشاعر في تأكيد الدلالات ؛ليثبت في نفس المتلقي كنز الصبر ، وينزع وتد الجزع والهلع من أعماقها؛ لذلك من الملاحظ تكرار الجمل التي تهدف إلى تثبيت المعنى المركزي في القصيدة. أرى الصبر محموداً

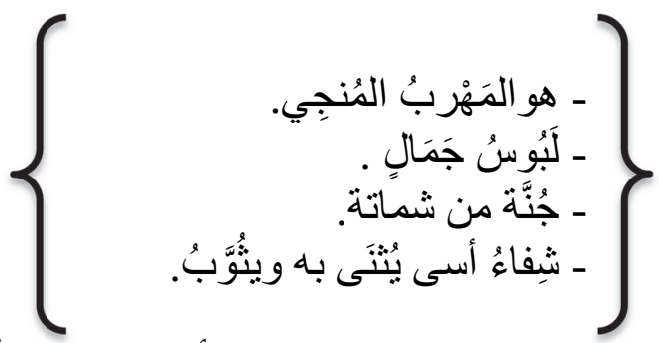

في الشكل التوضيحي السابق تأتي جملة (أرى الصبر محمودًا) ممثلة للمعنى الإجمالي لقيمة الصبر في حياة الإنسان التي تعاقبت جمل الإطناب في توضيحه،معالجة لبُعد النفس عن الصبر ،وسرعة اختيارها للجزع مهربًا.في هذا التعدّد الدلالي ــمثّل ابن الروميّ الصبر كمدوح لله من الخصال ما يجعله سيد الأخلاق، وأعظم ما يمتلكه الإنسان في حياته. وفي مثال آخر لاستخدام ابن الرومي للإطناب نسق هذا البيت المعتمدُ على تكرار معنى وجوب الصبر هنالك يَحِقُ الصبرُ والصبرُ وما كان منه كالضرورة أوجبُ

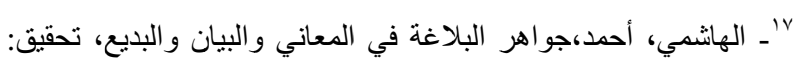

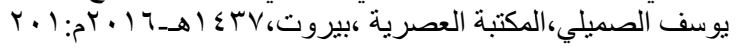

الأخرى أ" ، يشمل هذا التعريف أنواع التكرار ويؤكد على الوظيفة الدلالية التي يحققها، فالتَّكرار فيه نقطة التقاء مع التأكيد، فإتيان المتكلم بلفظ ثم إعادته سواء كان اللفظ متفق المعنى الأول والثاني، فإن كان متحد الألفاظ والمعاني، فالفائدة في إثباته تأكيد ذلك الأمر وتقريره في النفس '،فلا تقف أهمية التكرار عند الإيقاع والموسيقى بل تمتثُّ إلى الفعالية الدلالية فمن خلاله يمكننا الكثف عن حال المبدع " فالتكرار يسلط الضوء على نقطة حساسة في العبارة ويكشف عن اهتمام المتكلم به، وهو بهذا المعنى ذو دلالة نفسية قيمة تفيد الناقد الأدبي الذي يدرس الأثر ويحلل نفسيّة صاحبه " . 17 وبالنظر إلى ظاهرة تعدّد مفردة الصبر يتضح أنها وردت في النص مكررة تسع مرات موزعة في القصيدة؛حيث بدأ ابن الرومي القصيدة بتكرار الصبر ثلاث مرات في البيت الأول والثاني تأكيداً على وجوب الصبر، و ذكرت يُفردة الصبر ثلاث مرات في الأبيات الأخيرة توضيحًا لعاقبة الصبر .وعليه نجد أن هذا التناسب بين المطلع والخاتمة جاء لغاية جماليّة بلاغيّة تتطّلبها دلالة السياق

وكان للتكرار بالإطناب دور دلالي في هذه القصيدة فالمقصود بالإطناب: "زيادة اللفظ على المعنى

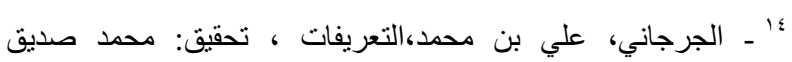

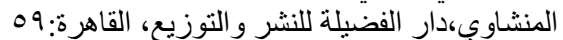

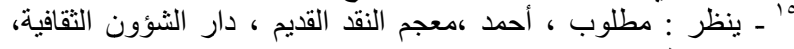

$$
\begin{aligned}
& \text { بغداد،ط: }
\end{aligned}
$$

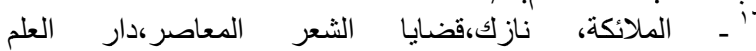

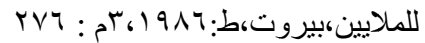


ولعل التركيز على هاتين الظاهرتين الدلالتين لبروزهما ووضوحهما في القصيدة فجاء البناء الدلالي

$$
\text { معتمد عليهما. }
$$

ثانيا: الدلالة الصوتيّة

يتميز الشعر عن غيره من الكتابات الأدبيّة بالوزن والقافية ويهتم بالغناء والإيقاع فبواعث الغناء هي عني أيضا بواعث الثعر ففي الغناء موسيقى النغمات والألحان، وفي الشعر موسيقى الوزن والألفاظ

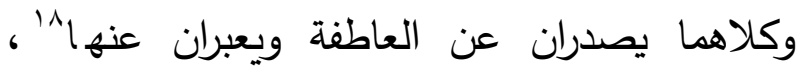
وللصوت حضوره في أدب ابن الرومي الذي يميزه عن غيره من الثعراء، فالبنية الإيقاعيّة في هذه القصيدة ذات دور فاعل في إيضاح دلالات المفردات والتراكيب، فالوحدة الصوتية التي شكلتها الانزياحات الصوتية التي اعتمد عليها ابن الروميّ كانت مصدرًا من مصادر الكثف عن المعاني، فيتزامن الصوت مع المعنى في نقل التجربة ورسم

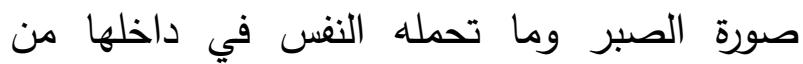
منازعات من إقبال وإدبار، ونعرض لهذا الملمح الأسلوبي من خلال ما يأتي:

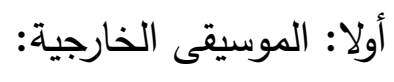

الوزن: يعد الوزن في الشعر عنصرا فعالا يمكن الثاعر من رسم لوحته الشعرية ونقلها للآخرين؛

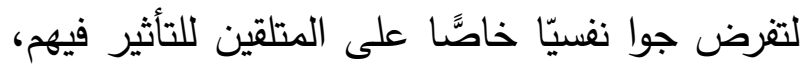
فالوزن جزء من المستوى الشعوريّ والفكريّ الذي يقوم عليه الشعر ، و للشعر أوزان وأعاريض متعددة تمكن الثن
جمل متعددة تلتقي في غرض دلاليّ مشترك يهدف إلى جذب النفس لاتخاذ الصبر خليقةً ثابتة مهما تقلبت أحوالها.

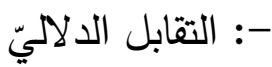
اعتمد البناء الدلاليّ في هذه القصيدة على ظاهرة التقابل، فجاء هذا النمط التركيبيّ متناسبًا مع أسلوب الخطاب المتبع في هذه القصيدة في مخاطبة النفس.

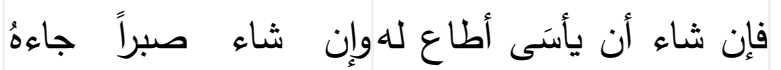

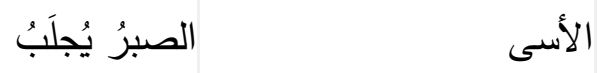
تمثل التقابلات في الأبيات السابقة صراع الإنسان مع الصبر ، فهو ما بين شد وجذب يحكم اليأس عليه

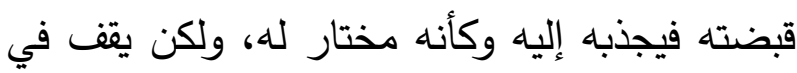
مقابلة ذلك من أختار أن يكون صابرا جمع عزمه وفيه

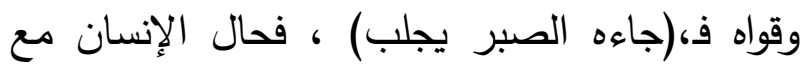
الصبر حال إقبال وإدبار (يراد فيأتي أو يذاد فيذهب) ،فهو في صراع دائم مع الجزع الذي قد يهزمه وهو

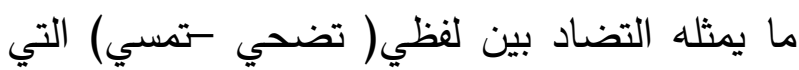
دلت على اتصال الحال والتي لا تنفك عن النفس اليائسة الغارقة في الجزع والهلع. وتتميز هذه التقابلات بالتعاضد اللفظي حيث تتراصف الكلمات

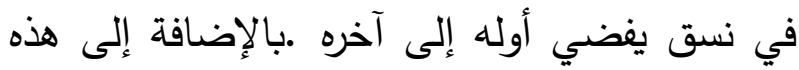

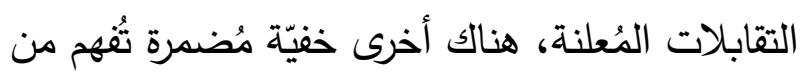

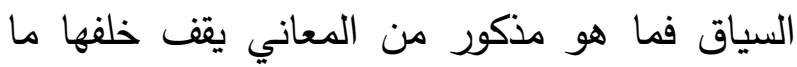
يقابلها من المذموم في فلسفة الصبر . مون 
صوت هذا الوزن الثعري بتفعيلاته القوية: ( فعولن

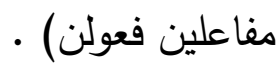
أرى الصبر محمودا وعنه مذاهب فكيف فعرئ إذا ما لم يكن عنه مذهب

فعولن مفاعيلن فعولن مفاعلن فعولن مفاعيلن فعولن مفاعلن هناك يحق الصبر والصبر واجب وما كان منه

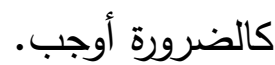

فعولن مفاعيلن فعولن مفاعلن فعولن مفاعيلن فعولن مفاعلن عبر هذا البحر في تفعيلاته الصوتيّة التي توحي

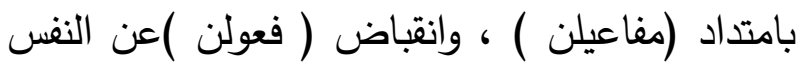

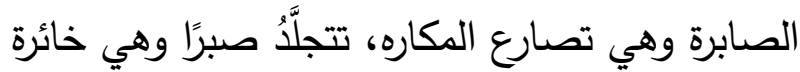

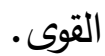

فتضحي جزوعا إن أصابت مصيبة وتمسي هلوعا إن تعذر مطلب . فتحقق للقصيدة من خلال خصائص البحر التعبير عن معنى الصبر وما يحتاجه هذا المعنى من اتساع دلالي يعبر عن معاناة الصابرين وما تحمله نفوسهم من صراعات، فكان هذا البحر ناقلا لزفرات وخلجات النفس التي تحمل ثقل الصبر ويتجاذبها معه الجزع والهلع.

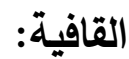

ويقود الحديث عن الوزن للحديث عن القافية، فهما عنصران متلازمان في الشعر العربي، عدها النقاد جزءا من الوزن ولها أثرها في العملية الشعرية، فهي
الشعراء من نظم المعاني المختلفة، فيكون للشاعر الحرية في اختيار الوزن الشعريّ الذي يستوعب لهب لهبه

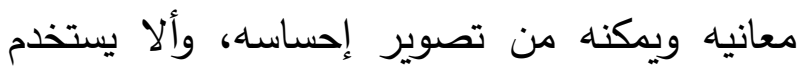

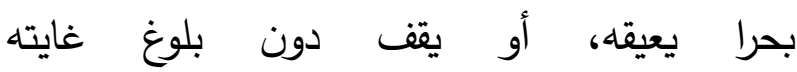
المنشودة، و'بالوقوف على وزن ابن الرومي نجد أنه استخدم البحر الطويل، وهو بحر ضخم، يستوعب المعاني، ويتسع للفخر والحماسة والاستعارات والتشبيهات وتدوين الأحداث ووصف الأحوال وسرد ولتح

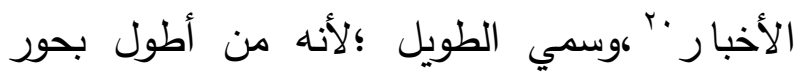

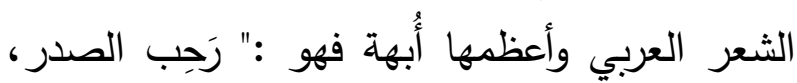

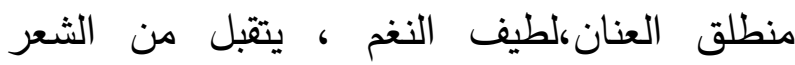

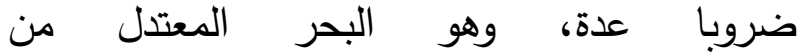
البحور" "rوعُرف عن البحر الطويل أنه من البحور ذات النغمة اللطيفة، فهو يخلصُ إلى السامع ولا يكادُ لهُ لهُ يشعر به، إذن بحر الطويل له سماتُّ تجعل للشاعر الذي ينظمُ فيه القدرة على الخروج بقصيدته من معنى إلى آخر ومن موضوع إلى سواه مع اتزان النسق واطراد في الجزالة، واستقطاب كافة التجارب الشعورية r'، وقد نظم ابن الرومي فيه هذه القصيدة

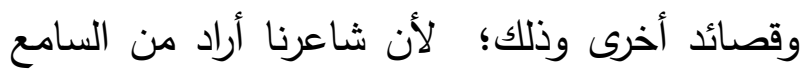

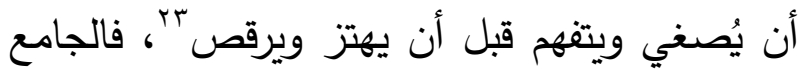
بين بحر الطويل وقصيدة (أرى الصبر) هو ما أداه

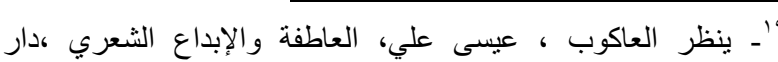

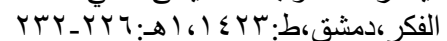

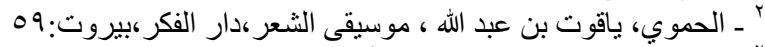

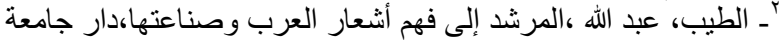

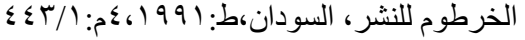

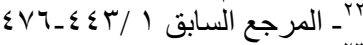

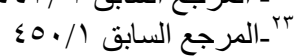


تزول إلا بالصبر، وبعد فقد أعطى اختيار الثاعر

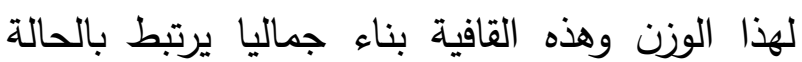
الثعورية للثاعر ويعكس أثاره على المتلقي. ثانيا- الموسيقى الداخلية : تتفاعل الموسيقى الداخلية مع الموسيقى الخارجية في البنية الإيقاعية للقصيدة، والتي تتمثل في اختيار الثاعر لصوت حروفه وألفاظه التي هي جزء من بناء دلالات النص، وقد استخدم ابن الرومي تقنيات صوتية ممثلة لانزياحات عديدة أظهرت براعته في نقل المعنى في مقدمتها استثماره لخصائص الحروف لإنه (الهمس، الجهر ، الرخاوة، الثدة)،فأحسن ابن الرومي

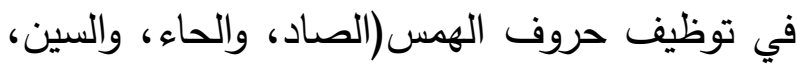

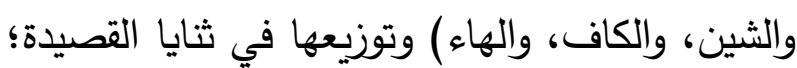

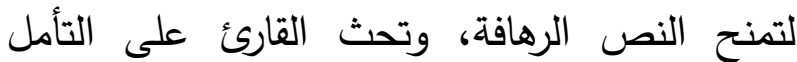

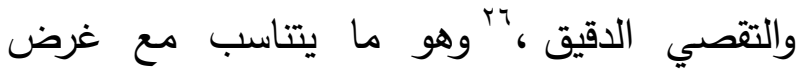
النص، فمدارج الصابرين لا يصل إليها إلا من كان متأملا لجمال عاقبة الصبر حيث الراحة بعد العناء والفرج بعد الشدة. فيا عجبا للشيء هذي خلاله وتارك ما فيه من

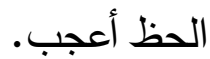

ولكن كانت الغلبة للأصوات المجهورة (الباء، الجيم، العين، اللام، النون) عند الحديث عن صفات الصبر وكأنها ترسم بنغتها حكاية صوتية لرحلة شاقة لرنة

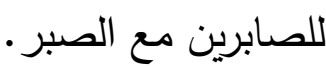

"ـ ينظر : الجيار ، شريف سعد، شعر إبر اهيم ناجي، دراسة أسلوبية بنائية

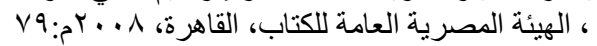

تفتح للشاعر آفاق القول وتمكنه من تصوير تجربته الشعورية ؛'، وجاءت قافية ابن الرومي في قصيدته:

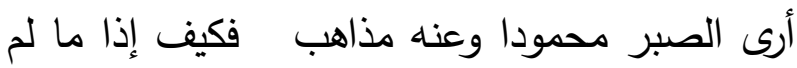

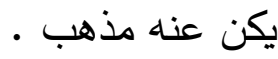
بائية مطلقة، والقافية المطلقة " ما كانت متحركة الروي أي بعد رويها وصل بإشباع بالكسر أو الضم

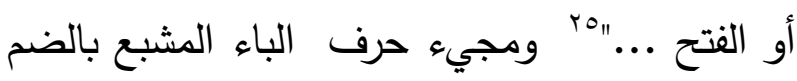
وهو حرف جهوريّ شديد انفجاريّ للروي يتناسب مع

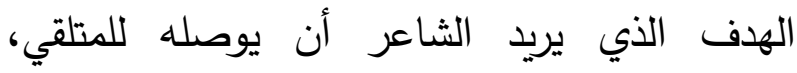
فشاعرنا ينادي بصوت عالي واضح على ضرورة التمسك بالصبر، فصوت(الباء) بشدته وجهره لاءم غرض الحكمة التي ينادي بها، وهي التحلي بخلق الصبر، وتدريب النفس الإنسانية على مشقته،

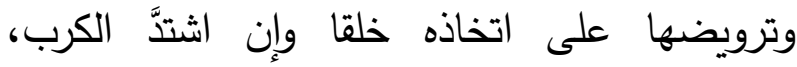
وضاقت النفس، واقتربت من هاوية الجزع، فجاءت القافية في كل بيت (مذهب، أوجب، مهرب، تتعتب) نغمة قويّة تقرع العقول نحو معنى البيت، وقد جاء

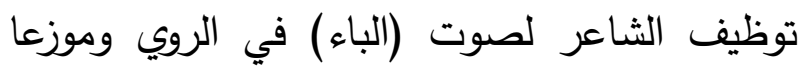
في القصيدة منسجما مع حالته النفسيّة التي اتسَّمت بالغضب من الحياة وحالات التوتر والقلق والعتاب التي عاشها الشاعر، فهو يعبر عن انفجار مشاعره تجاه من لا يتمسك بالصبر أو يتحلى به، وهذا

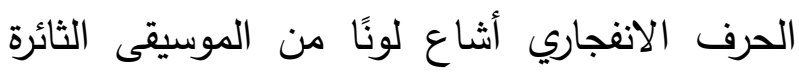

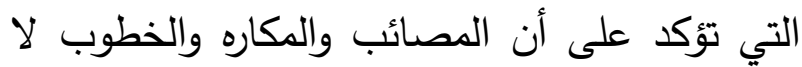

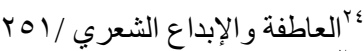

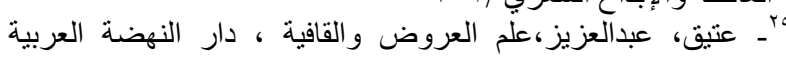

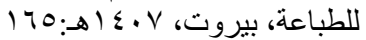


الثعر يزبد من موسيقاه، فتكرار الصوت في البيت أو في القافية يجعل القصيدة أشبه بلوحة موسيقية

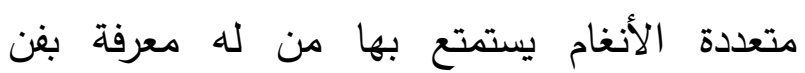

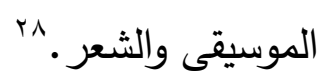

وكثرت المحسنات البديعيّة عند ابن الروميّ، والتي ولتي

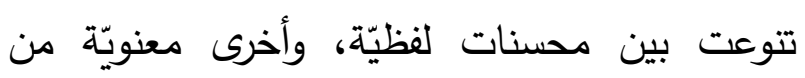
أهمها توعات ما يأتي: - المها: الطباق والمقابلة: من البنى الإيقاعيّة التي تجلت في القصيدة بصورة واضحة فهي تقوم بربط الجمل بالسياقات التي تكون ملائمة لها ومن بين هذه واهن الصور التعبيريّة لبنية الطباق قوله:

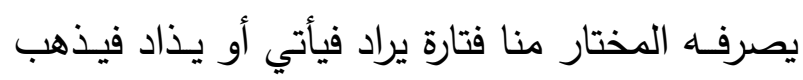

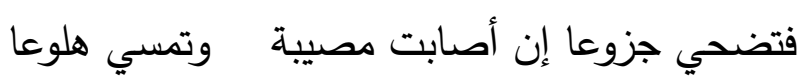
إن تعذر مطلب. أعطى التضاد اتصال الحال، فالنفس التي لم تُهذب

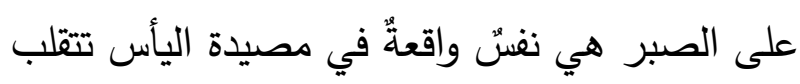

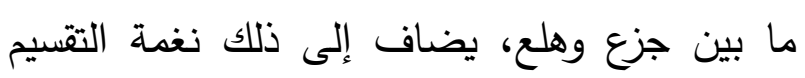

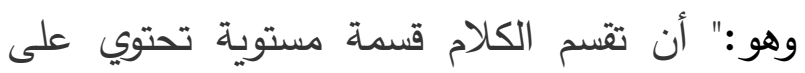

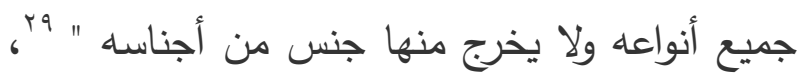
ولقد استخدم الثاعر التقسيم من خلال تقسيم ألفاظ البيت إلى مقاطع متقاربة أو متساوية صوتياً،بحيث يستوفي المتكلم أقسام المعنى الذي هو آخذ فيله،

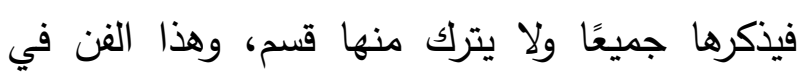

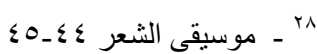

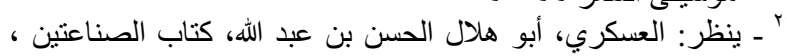

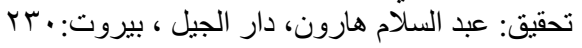

هناك يحق الصبر والصبر واجب وما كان منه

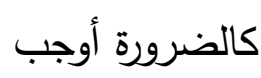
فثد امرؤ بالصبر كفا فإنه له عصمة أسبابها لا تقضب فمن الملاحظ ما لهذين البيتين من صوت قوي

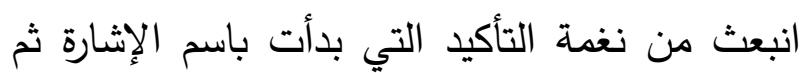

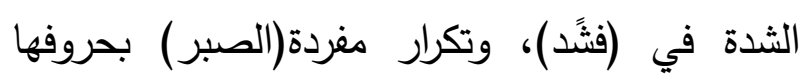
الصاد الصفيري والباء المجهورة ثم انغلاق الثطر فئرد بمفردة واجب التي اشترك الروي الباء في رسم قوتهاء كمفردة تلزم الإنسان التمسك بالصبر؛ فهو وسيلته

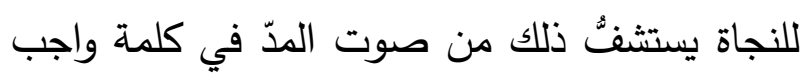
فسمة حروف المد أنها تفرض على المتلقي قراءة الأبيات ببطء وتأن، ولو أراد الإسراع ما أمكنه ذلك لكروفي

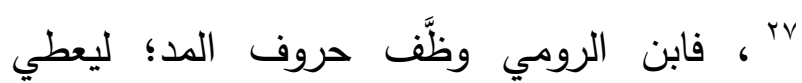

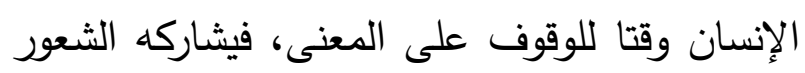
ويتفاعل معه . وتتجلى الموسيقى الداخلية في استخدام ابن الرومي

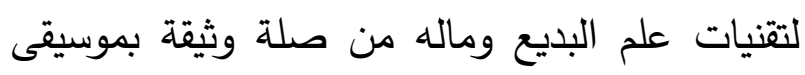
اللفظ، فهو في الحقيقة تتميق وتحسين الكلام لفظا ومعنى حتى يكون لله نغم وموسيقى تجذب الأسماع

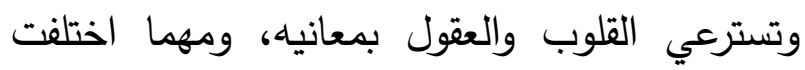
المحسنات البديعية وتعددت طرقها إلا أنه يجمعها وتها أمر واحد هو العناية بجَرسِ الألفاظ ووقعها وتأثيرها

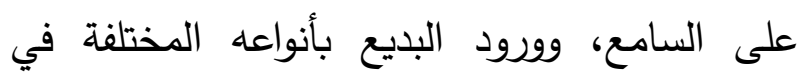

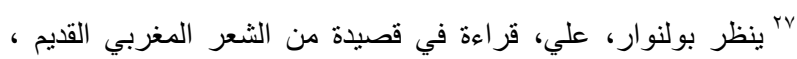

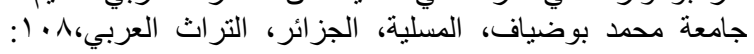

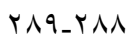


وتحسين قصيدته بهذا المحسن البديعي الذي أطلق

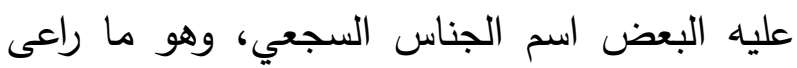
فيه شاعرنا المكان من الكلمات التي استعملها في وهو ماني

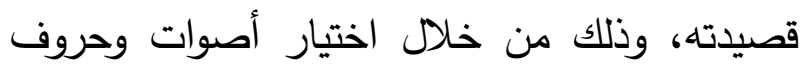

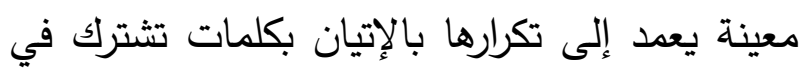

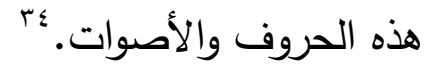
وقد أدت طبيعة المجانسة عند ابن الرومي دورًا بارزًا

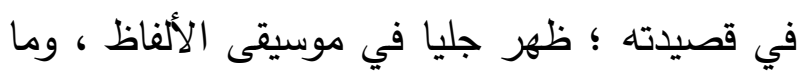
تقوم به من تفاعل بين الدلالة والسياق الذي ترد فيه،

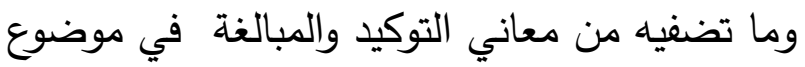
الصبر، فاستخدام الانزياح بالجناس ليس مجرد اختيار صوتي فقط ؛ وإنما يفضي إلى علاقة دلالية

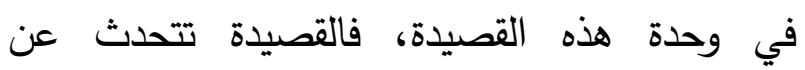
موضوع الصبر ولا تغادره، فكل بيت فيها يستدعي البيت الذي يليه، وقد أجمع النقاد على هذه الوحدة،

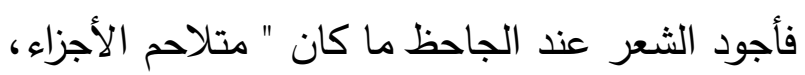
سهل المخارج، فتعلم بذلك أنه أفرغ إفراغا واحدا وسبك سبكا واحدا". ro

البنية الإيقاعية لدى ابن الرومي بنية خاصة أطلق

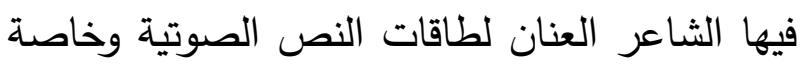
ما كان منها قادرا على بناء وحدة صوتية، فاعتمد على ربط المعنى كما يظهر في استخدامه للمحسن البديعي (ردَّ العُجز على الصدر) ويُعرّف هذا الملمح

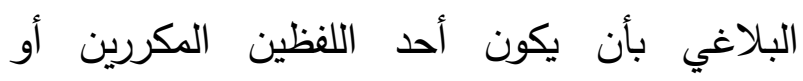
المتجانسين أو الملحقين بالمتجانسين بطريق

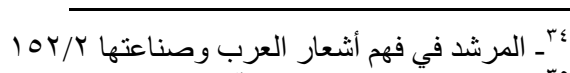

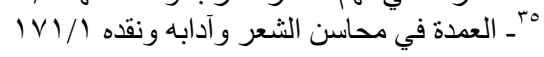

القصيدة قام على تقسيم الكلمات على أساس الوزن،

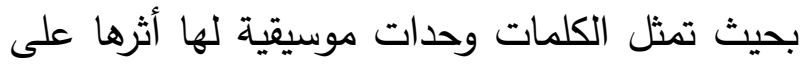
السامع، كما تجعل للبيت جرسا موسيقيا.

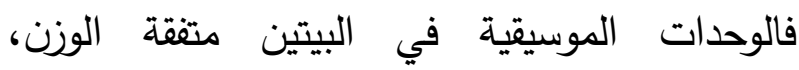
والكلمات (يراد) (يذاد) (يأتي) ( يذهب) (تضحي) (تمسي) (جزوعا) (هلوعا) جاءت على وزن صرفيّ واحد، مما أعطى القصيدة إيقاعًا موسيقيا مؤثرا. ومن مصادر موسيقى القصيدة ذلك الارتداد الصوتي موني الصني النغمي الصادر عن الجناس حيث يعد التجنيس أو التجانس أو المجانسة من أبرز الظواهر الإيقاعية في

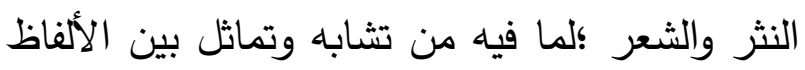
المتجانسة، وقد تداوله القدامى في كتبهر. •"، ويتكون من:" مقطعان صوتيان متفقان في الإيقاع مختلفان

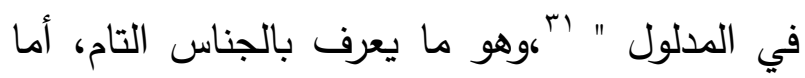
الناقص فهو " مقطعان صوتيان مختلفان في الإيقاع

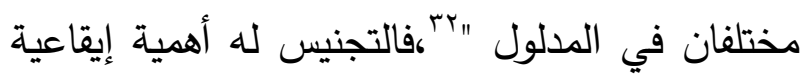

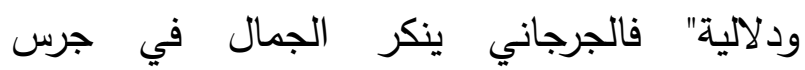
الأصوات، ويرجع سر الجمال في الكلمة أو الكلام إلى دلالة الألفاظ" وبرجع سترات وقد ورد الجناس غير التام في قصيدة الصبر ، وهو الأكثر شيوعا في القصيدة نحو:( مذاهب - مذهب، واجب - أوجب، عجبا - أعجب، يأسى - الأسىى) تظهر -هنا- براعة الثاعر في القدرة على تتميق،

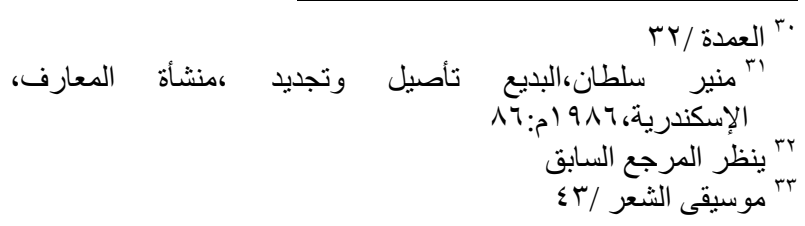


لا يعرض فلا يسعى في طلبه إلا نادرا، لإبراز معنى

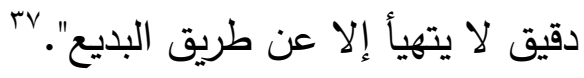

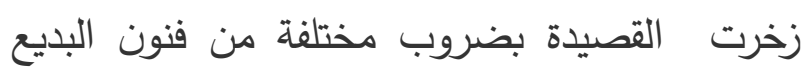
دن جناس وطباق تقسيم وتصدير، ولا عجب في من في

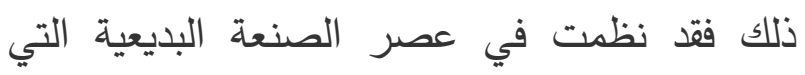
سيطرت على منظومة الأدب العربي، فأضفت فنون البديع سمة جمالية إيقاعية كثفت عنها النغمة النهاب الداخلية من خلال الكلمات، وكان لها تأثيرها الواضح في بلاغة الخطاب وإيصال مضمونه. المبحث الثاني: جماليات الأساليب

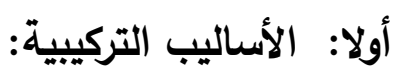
الأسلوب التركيبي من أهم العناصر التي تساهم في

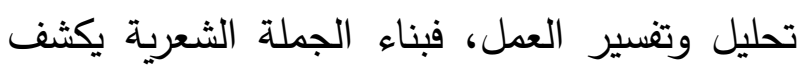
لنا معانيها على الوجه الصحيح، وقد قال الجرجاني:

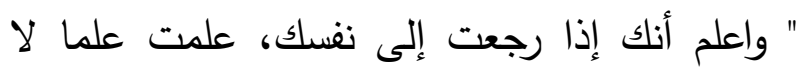

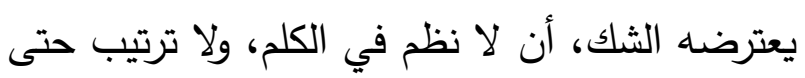

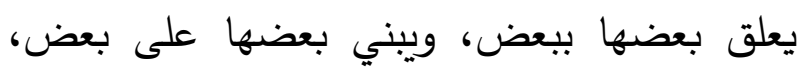

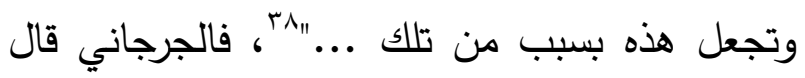
هذا ليثبت أن تركيب الجملة نظما لا بد أن يكون

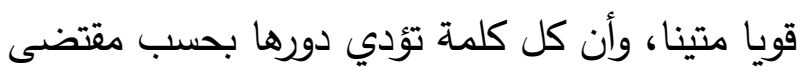

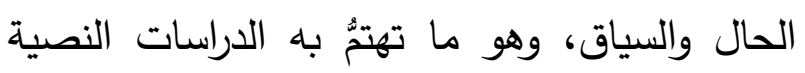

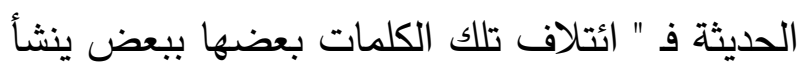

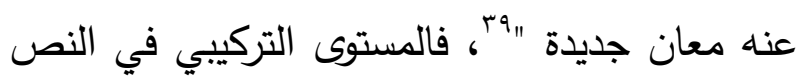

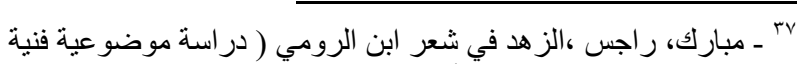

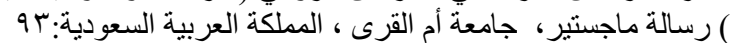

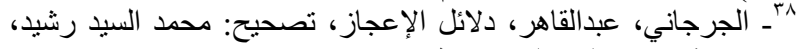

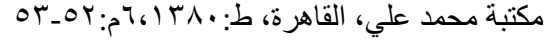
ج" بونس، محمد، وصفي اللغة العربية دلاليا ، جامعة الفاتح، طر ابلس،
الاشتقاق، أو أحد الملحقين بهما بطريق شبه الاشتقاق في آخر البيت، ويكون اللفظ الآخر المقابل

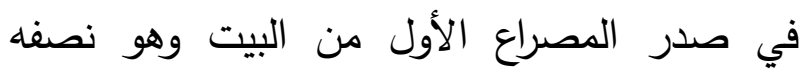
الأول، أو يكون في حشوه أو آخره، أو يكون ذلك الك وهن

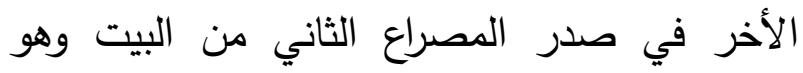
نصفه الثاني، بّهذا التوافق الصوتي كان له تأثيره الدلاليّ في ربط أجزاء المعنى كما في الأبيات

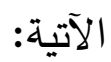

أرى الصبر محمودا وعنه مذاهب فكيف إذا لم يكن عنه مذهب هناك يحق الصبر والصبر واجب وماكان منه

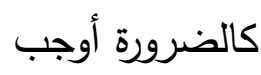
هو المهرب المنجي لمن أحدقت به مكاره دهر ليس منهن مهرب هذا الارتداد الصوتيّ لا يترك للسامع فرصة الخروج عن المعنى المراد، فليس الصبر خياراً، وليس فقط لآلئ واجبًا بل هو أوجبُ ولا مفرّ منه، وليس منه مهرب لهبر

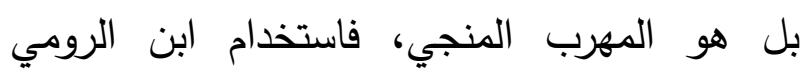
للصنعة البديعية أظهرت لنا مدى ثراء معجمه اللغويّ التيّي

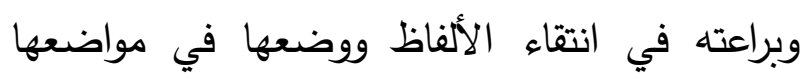
المناسبة والدالة على المعنى، دون أثر لاضطراب أو

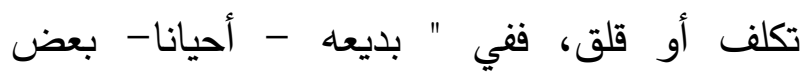

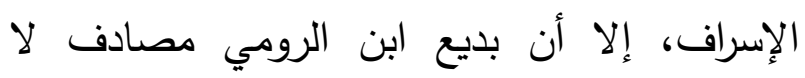

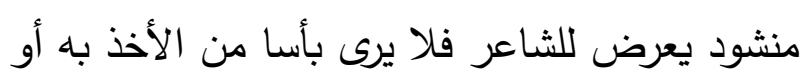


القصيدة، بينما ختم الشاعر القصيدة ببيت زاوج فيه

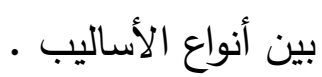

فلا يعذرن التارك الصبر نفسه بأن قيل إن الصبر لا يتكسب فالثطر الأول من البيت إنشائي نهي والثطر الثاني خبري مؤكد بأسلوب التوكيد، ليؤكد أنَّ فضيلة الصبر من مكتسبات النفس إن عود الإنسان نفسه على ذلك، ولم يتركها تهيم في هذه الحياة

والأسلوب الخبري يتناسب وتقرير الحقائق وغرض الحكمة الذي استهل باه ابن الرومي قصيدته، وتتوع الأسلوب الخبري بين جمل فعلية وأخرى اسمية فعلى الرغم من كثرة الجمل الاسمية في القصيدة والتي لجأ إليها ابن الرومي " للتعبير عن الحالات التي تحتاج إلى التوصيف والتثبيت ذلك أن الاسم يخلو من الزمن ويصلح للدلالة على عدم التجدد وإعطائه لونا من الثبات "•؛ إلا أن الجمل الفعلية قد تجاوزتها عددا، ولعل ذلك إلى ما تضفيه الجملة الفعلية من معاني التغيير والتجدد، وغلبة الفعل المضارع في القصيدة حتى يسبغ الشاعر على حكمه صفة التجدد والاستمرارية؛؛ لتبق صالحة لكلِ زمان ومكان، فالصبر ديدن النفس التي تبقى في حال تجديد لعهدها مع الصبر فكلما ارتخت همتها تذكرت ما للصبر من محاسن تهون عليها مرارته. - : الأسلوب الإنشائي :
يكشف عن اللغة الشعرية التي اعتمد عليها الشاعر في اختياراته وانزياحاته للكثف عن المقاصد، وقد جاءت كما يلي:

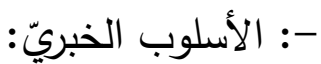

وقد استهل شاعرنا القصيدة بأسلوب خبريّ يقرر فيه صفات الصبر ، ثم يعقبها بأسلوب استفهام دال على التعجب والاستنكار ، ثم تتوالى الأخبار ؛ ليقرر حقائق وجماليات تتعلق بالصبر ، ثم يختم القصيدة بعك ر ما بدأبه قصيدته : فلا يعذرن التارك الصبر نفسه بأن قيل إن الصبر لا يتكسب فنلحظ من القصيدة أن الأسلوب الخبريّ هو الأسلوب الأكثر استعمالا، فهو يخاطب النفس الإنسانية ويدعوها للتمسك بالصبر وذلك من خلال بيان صفات الصبر وجمالياته؛ نحو: (أرى الصبر محمودا وعنه مذاهب) ، (هناك يحق الصبر والصبر واجب)،(هو المهرب المنجي لمن أحدقت به)،(مكاره دهر ليس منهن مهرب)،(لبوس جمال جنة من شماتة)،( شفاء أسى يثني به ويثوب)، فجاء اختيار الثاعر لبناء هذه القصيدة على هيئة أخبار مؤكدة للمعنى نفيا أو إثباتا، وهذا التتوع إنما جيء بـ لمحاصرة هذه النفس المتقلبة الهاربة من مشقة الصبر، فالأسلوب الخبري أسلوب تقريري مباشر، جيء باء ليؤكد على ضرورة التمسك والتحلي بالصبر ، يقابل ذلك الأساليب الإنشائية التي تخللت 
وقد يقع في المعاني ولكل مواطن يحسن فيها ويقبح "

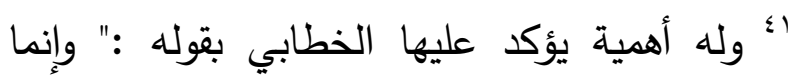
يحتاج إليه ويحسن استعماله في الأمور المهمة التي قد تعظم العناية بها ويخاف بتركه وقوع الغلط والنسيان فيها والاستعانة بقدرهاء؛ " ، فبنية التكرار

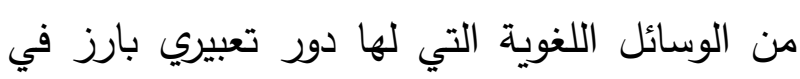
القصيدة، فتكرار الحرف أو الكلمة أو الجملة في أبيات الثاعر توحي بسيطرة هذا العنصر الككرر على فكر الثاعر وشعوره، لذلك يظهر بين لحظة وأخرى، فعد ابن الرومي إلى التوازي التركيبي بتكرار لفظ الصبر؛ لأنها تعتبر من الكعلى التهات الكفتاحية التي تعطي أبعادا دلالية وفنية؛ لذلك الكات تكررت في أول القصيدة وآخرها حتى تكون الرابط في بناء القصيدة معنويا ولفظيا . تكرار كلمة الصبر في القصيدة في قوله: أرى الصبر محمودا وعنه مذاهب فكيف إذا لم يكن عنه مذهب هناك يحق الصبر والصبر واجب وما كان منه

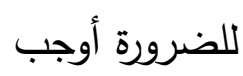
فلا يعذرن التارك الصبر نغسه بأن قيل إن الصبر لا يتكسب يمنح التركيب اللغوي المتكرر للمنى صفة الاستمرارية والامتداد، ويعيد للقصيدة حيويتها "- ــ عزام، محمد، المصطلح النقدي في التراث الأدبي العربي ، دار الثرق، بيروت: 19

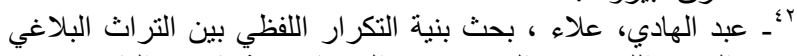

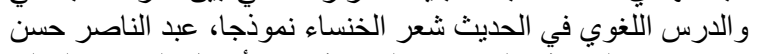

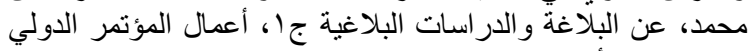

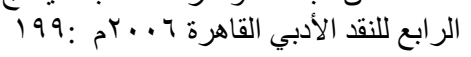

نجد أن الأسلوب الإنشائي أقل ورودا فقد استخدم أسلوب الاستفهام الذي خرج إلى معنى التعجب في الأني

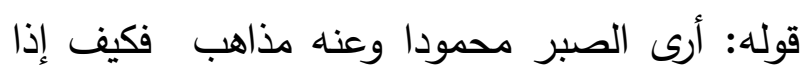
ما لم يكن عنه مذهب.

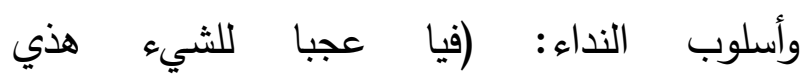
خلاله)،بحرف النداء (يا) التي تستعمل لنداء البعيد للتعجب والتتبيه ،فكأنه ينادي من أعماقه متعجبا لتاليا

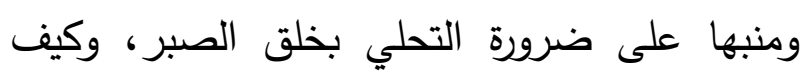
عنه يحيدُ ذو عقل. ويختم قصيدته بأسلوب إنثائي نهي:

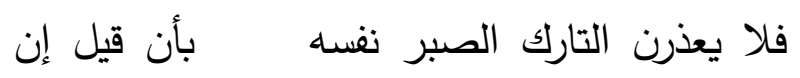
الصبر لا يتكسب من خلال ما تقدم نصل إلى أن كثرة وغزارة الجمل الخبرية في القصيدة يرجع إلى شخصية شاعرنا؛

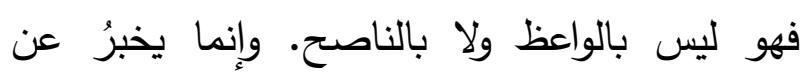

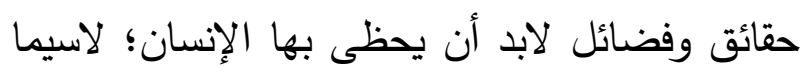

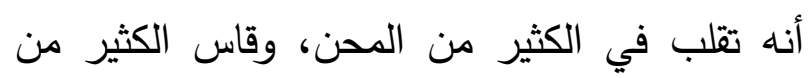
النكبات ما بين فقد الوالدين والزوجة والأبناء ،ولعل الكان قلة الأساليب الإنثائية في القصيدة يعود إلى رغبة النباء

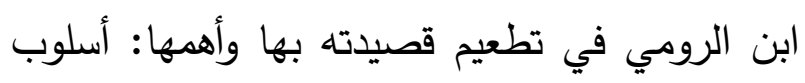
الاستفهام والنداء والنهي ؛ لإضافة نوع من الحيوية والتخلص من الرتابة. - - التكرار : نوَّع ابن الروميّ في استخدام الانزياحات التركيبية

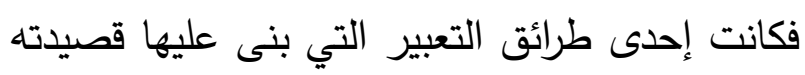

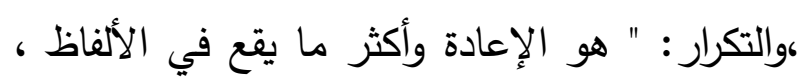


ولتجديد واستمرارية تفاعل المتلقي مع شاعرنا؛ لمعايشة تجربته الشعورية مع الصبر • ومن الملاحظ سيطرةُ حرف التاء على أواخر القصيدة في قوله : فتضحي جزوعا إن أصابت مصيبة وتمسي هلوعا أن تعذر مطلب فلا يعذرن التارك الصبر نفسه بـأن قيل إن الصبر لا يتكسب. ويعدُّ تَكْرَرُ الحروفِ من أبسطِ أنواعِ التكرار، وأقلّها

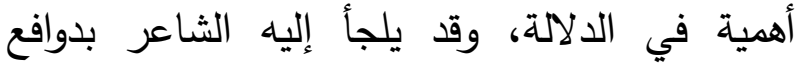
شعورية؛ لتعزيز الإيقاع في محاولة منه لمحاكاة

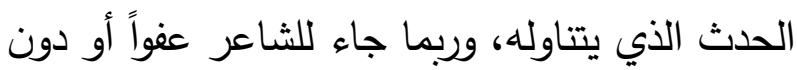

$$
\text { وعي منه" آن أن }
$$

نجد أن التكرار كان له دور في البنية التركيبة

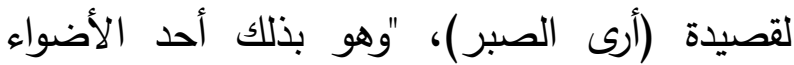

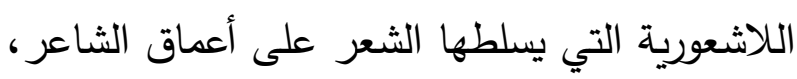

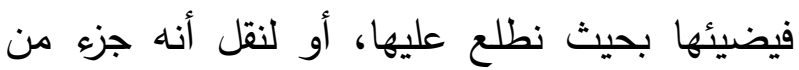

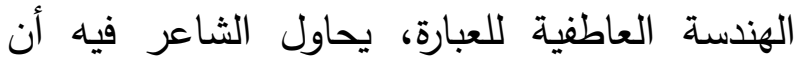

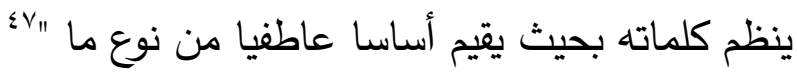
ثانيا: الأساليب التصويرية :

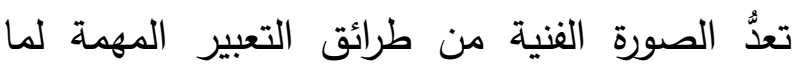
تُحدثه في المعاني من خصوصية وتأثير ، فتشد انتباه المتلقي للمعنى الذي تعرض لله، فتجعل المتلقي متفاعلا مع ذلك المعنى ومتأثرا به، فالصورة الفنية

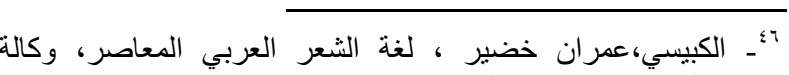

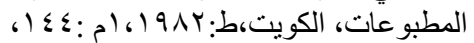

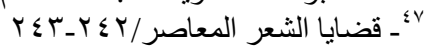

الإيقاعية من خلال الحركة الصوتية للكلمة فالمتلقي

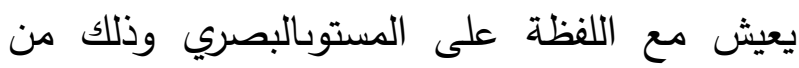
خلال التماثلات الخطية، والمستوى النطقي من ين خلال التماثل الصوتي باء، فجاء تكرار كلمة (الصبر) للفت الانتباه ولعلاقته الوثيقة بالسياق العام للقصيدة

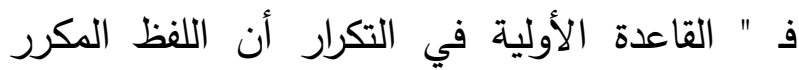

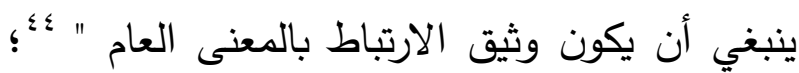

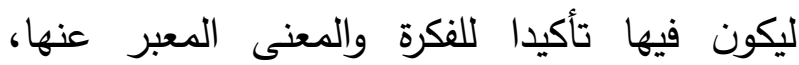
وحضور كلمة (الصبر) دلَّ على حال ابن الرومي التي ناءت بما تحمل، وتطلب الصبر ؛ ليكون الدواء لها، وتتصح به لكل داء فهو يروي بهذا التكرار

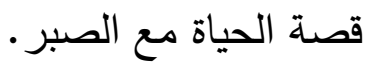
وتكرار الصيغة الصرفية هو نوع من الانزياح

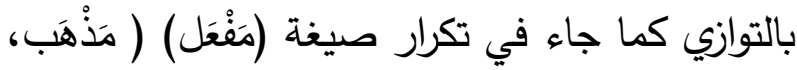

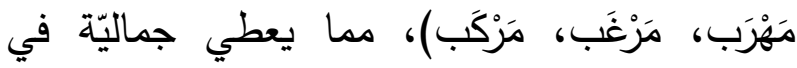
المعنى وفي موسيقى القصيدة، وهو نوع من الترديد الذي:" يساعد على تتمية الصورة الفنية واطراد نموها وحيويتها كما يساعد على إبراز التجربة الفنية للشاعر، فلا يصرفه عن هدفه الأساسي الذي أنشئ

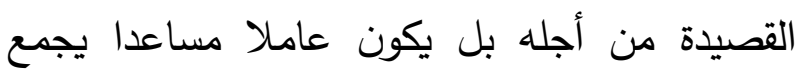

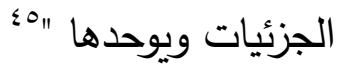

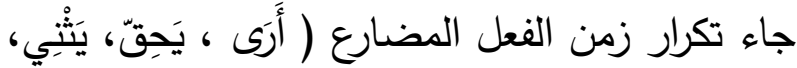

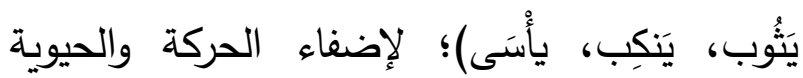

$$
\begin{aligned}
& \text { rاء عسران، محمود،البنية الإيقاعية في شعر شوقي، مكتبة المعرفة، }
\end{aligned}
$$

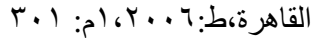

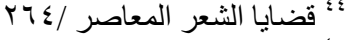

$$
\begin{aligned}
& \text { ه؛ ـ الثيخ، عبدالواحد حسن، البديع والتوازي ، مكتبة الإشعاع الفنية، }
\end{aligned}
$$

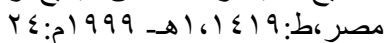




$$
\text { نور بنت عويض الرفاعي }
$$

v.

النفوس، وأقرب وصولا من الصور التقريريّة الوصفيّة

وقد بدأ ابن الرومي لوحته الشعرية باستعارة مكنية :

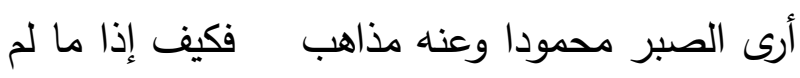
يكن عنه مذهب.

رسم لوحته بريشة تجسد وتشخص الصبر في صورة

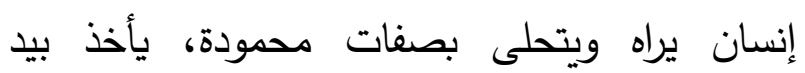
صاحبه ويعصمه من الوقوع في الصعاب في قوله:

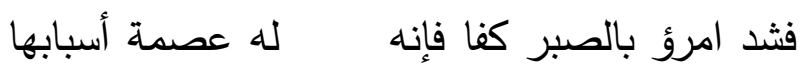
لا تقضب. فالاستعارة تمزج بين الشعور واللاشعور ، و" تسهم في الكثف عن طبيعة الإنسان الحقيقيّة بما هي صدى للشعور " .0، وبالتالي تمكننا معرفة أغوار المبدع، وذلك من خلال تكثيفه واهتمامه بصورة

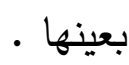
فالمستوى التصويريّ لاى ابن الرومي يجعل من

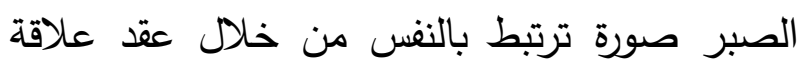

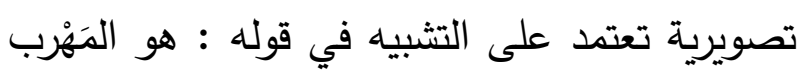

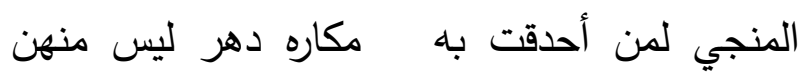
مهرب نرى هنا صورة الإنسان المحاصر بمكاره الدهر، وقد ضاقت به فلا مهرب منها إلا بالصبر فهو المهرب

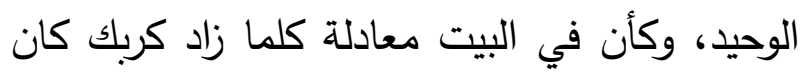

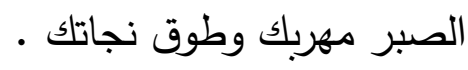

9؛يظر: نافع،عبد الفتاح، الصورة في شعر بشار بن برد، دار الفكر،

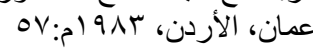

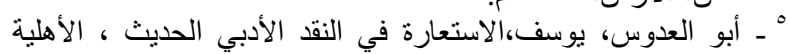

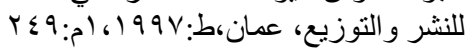

تحوي المعاني المجردة المكتملة، وتحدث فيها خصوصية وتأثيرا متفردا، يقوم على ما تحمله من

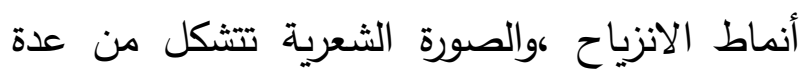

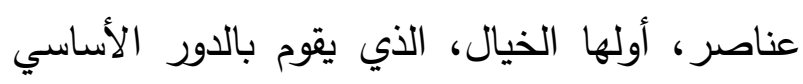

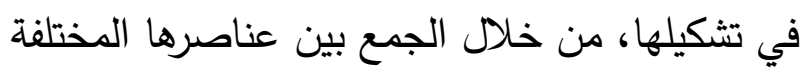

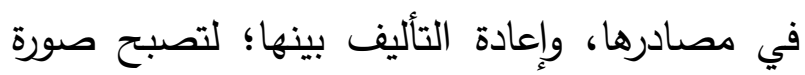

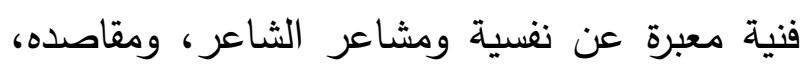

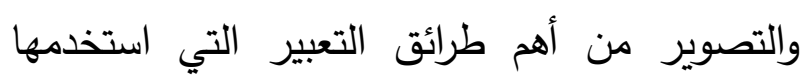

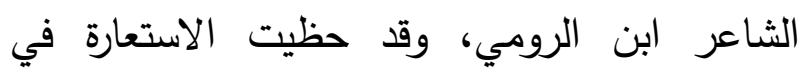
قصيدة ابن الرومي بمنزلة كبيرة فورود الصورة الروبية الاستعارية في قصيدة الصبر كثفت عن مهارة

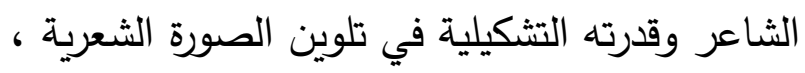

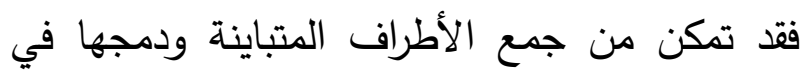
صورة واحدة، وجاء اختيار الثاعر للاستعارة دون لهن

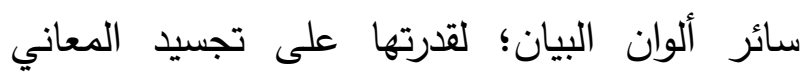
المجردة وذلك من خلال" صيرورة المعنى والخاطرة إلى هيئة بارزة محددة تقع تحت الحس وتجسم الفكرة

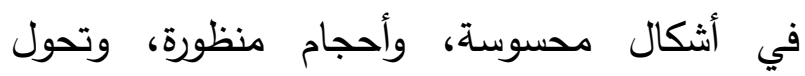
التجريد المطلق إلى صورة منظورة وعوالم مرئية فالمعول في التجسيم لا على المشابهة والمضاهاة كما في التشبيه الحسي الخالي من الشعور بل المعول فيه على التبديل والتحويل والتغيير والتصيير "ئومما لاشك فيه أن الصور التي تحظى بعنصري التشخيص والإيحاء تكون أبعد تأثيرا في لاتئ

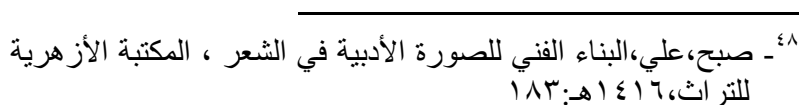


فتضحي جزوعا إن أصابت مصيبة وتمسي هلوعا إن تعذر مطلب.

تقع الصورة بين الثنائية الضديّة للأفعال ( تقاتل - تغلب) فيصور صورة صراع النفس الواهية الضعيفة التي لم تتزود بالصبر فهي في عالم

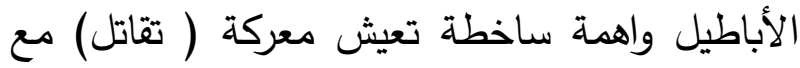
القضاء والقدر بسلاح واه وهو(العتب)، لتعلن هزيمتها في نهاية المعركة، وهو ما تمثله دلالة الفعل وهن (تغلب) فهو المصير المحتوم لكل نفس لم يكن سلاحها الصبر والتجلد ومجاهدة النفس عليه. وما يعضد ذلك الصورة التقابلية في البيت الثاني :

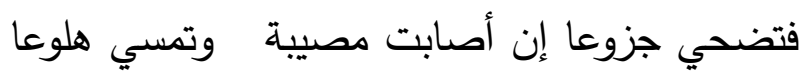
إن تعذر مطلب. فالنفس التي خلت من روح الصبر والثبات هي نفس عهل

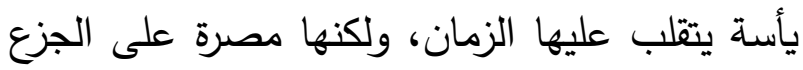

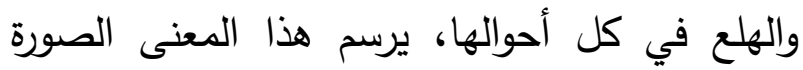

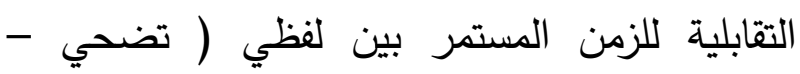
تمسي) الدالين على اتصال الزمن وثبات الحال

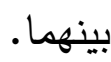
ويختم الثاعر قصيدته ببيت: فلا يعذرن التارك الصبر نفسه بأن قيل إن الصبر لا يتكسب. يصور البيت علاقة خاصة بين الإنسان والصبر لإن لإن إلبر علاقة تلازم، ليؤكدأن فضيلة الصبر من مكتسبات

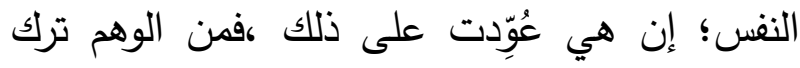

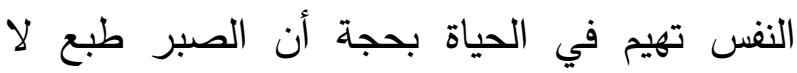
يكتسب، ليتسلل لها الوَهْن من هذا الباب فتخور قواها
ومازال ابن الرومي يتغنى ويشيد بصفات الصبر،

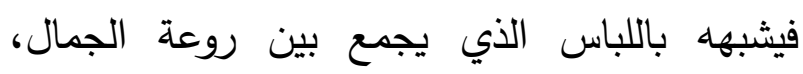
والقدرة على الحماية، وبالدواء الذي يشفي صاحبه

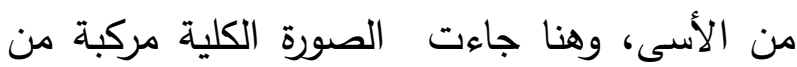

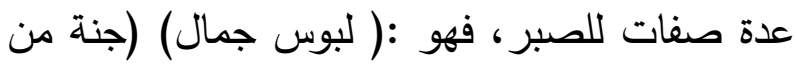
شماتة) ( شفاء أسى)، فتجسيد الصبر بهذه الألفاظ شكل صورة شعريّة مكنته من إضفاء الصفات الحسنة عليه، مما أكسب النص نكتة جمالية، مزجت بين الصبر والإنسان في علاقة ترغيب، لا انفكالك له عنها ولم تكن الصورة التثبيهيه فقط هي وسيلة ابن الرومي في رسم صوره الشعريّة في قصيدة ( أرى في فئ الصبر) ففي قوله: فإن شاء أن يأسى أطاع له له الأسى وإن شاء صبرا جاءه الصبر يجلب. يعقد ابن الرومي صورة تقابليّة بين الأسى والصبر مدارها الإنسان صاحب القرار، فهو يجعل الإنسان مخيرا بين حاليين ويترك له حرية الاختيار فهو من يملك القرار،فهو بهذه الصورة يضع النفس في لهي مواجهة مع اختيارها فلم يجني عليها أحد غيرها، فمن صبر فله العاقبة الطيبة ومن جزع فله العاقبة

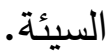
ويستمر ابن الرومي في تصوير الصراع النفسيّ للنفس الإنسانيّة فيقوله: وإن هو مناها الأباطيل لم تزل تقاتل بالعتبن

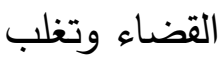


جسَّم المعاني وشخَّصها، وأضفى عليها كل ما للأحياء من خواص، وصفات يبوح لها بما ضاق به

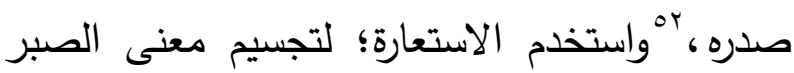
تجسيما محسا تدركه الحواس؛ لقدرتها على الإفهام، وكثف ما خفي في صورة واضحة الخطوطّهـ وقد برع ابن الرومي في تشخيص المعاني المجردة،

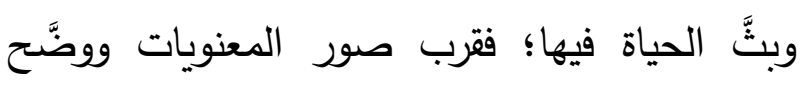
معالمها، ونقل حكمته إلى المتلقي بشكل صورة صنه

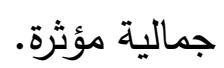

\section{الخاتمة}

اجتهدت هذه الدراسة لقيدة أرى الصبرَ محمودًا)لابن الروميّ في الوقوف على النسق البنائي

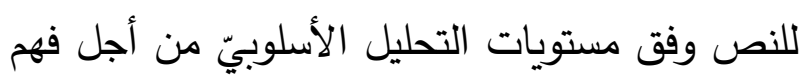
معانيه، والكشف عن جمالياته، فخرجت بعدَّة نتائج:

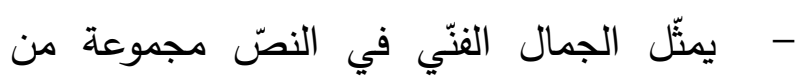
الظواهر المترابطة والتي تتعكس من خلال مستويات

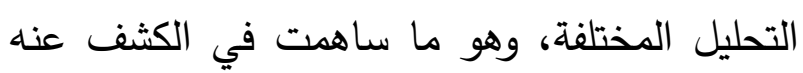

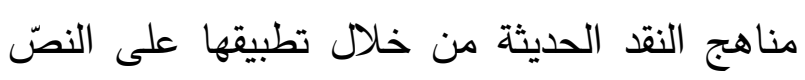
الأدبي القديم واستتطاق جمالياته.

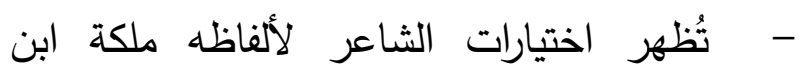
الرومي في النفاذ إلى باطن المعنى؛ فهو بعدد

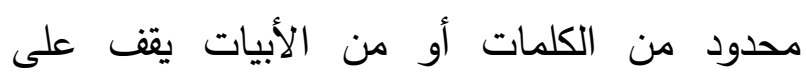
مضمون الدلالي، فكان للمفردة دورها في إظهار

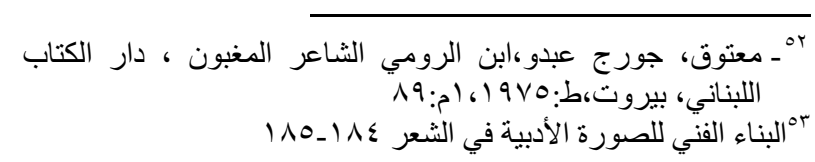

،نجد أن القصيدة اعتمدت على الانزياح التصويري

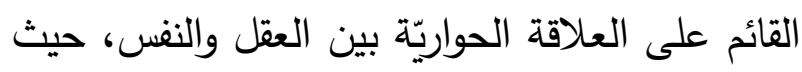
جعل النفس مخاطبا: إذا احتجّ محتجّ على النفس لم تكد على قدر يمنى لها تتعتب إداج ويصور حالها مع العقل، فالعاقل من ساعدها على الصبر وذلك في قوله: وساعدها الصبر الجميل فأقبلت إليها طوعا جنائب نجنب وخائب من مناها الأباطيل نحو: وإن هو مناها

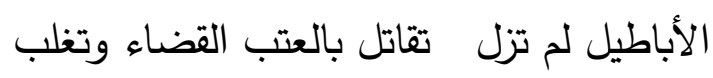

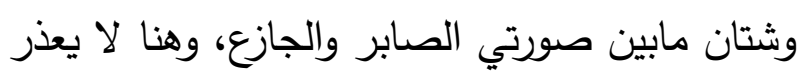

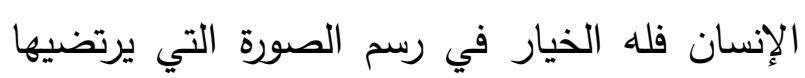

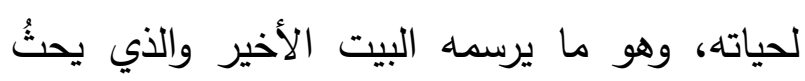
على اكتساب الصبر فلا يعذرن التارك الصبر نفسه بأن قيل إن الصبر لا يتكسب. من هنا نرى أن الأساليب التصويرية هي إحدى الوسائل البلاغية التي تحقق الجمالية في النصّي النيّ الشعريّ فَ" الجمالية التي يقِّمها النص الإبداعي لئي سواء كانت صورًا وصفيّة، حسيّة، أو إيحائيّة أو الأبري

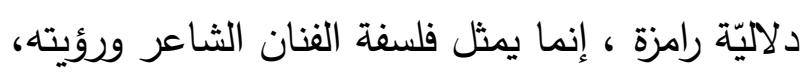
ودرجة حساسيته إزاء العالم "، "ولعل كثرة استخدام ابن الرومي للتشخيص جاء تحت تأثير حساسيته الخاصة، ولما عرف عنه من الإحساس المرهف، فقد الرد

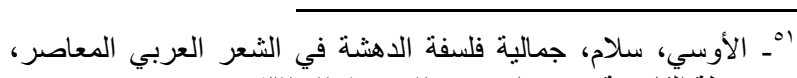

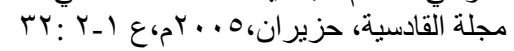


مكامن المعاني في القصيدة، كذلك كان لالالة دلاليّ يعبّر عن معاناة الصابرين، وما تحمله نفوسهم من صراعات. - أعطت القافيةُ البائيةٌ في هذا الحرف الانفجاريّ لونًا من الموسيقى الثائرة التي تؤكّد على أن المصائب والمكاره لا تزول إلا بقوّة الصبر • - أحسن ابن الروميّ في توظيف خصائص الحروف الصوتيّة من همس وجهر وتوزيعها في ثنايا القصيدة متناسبة مع غرض النصّ،فكانت الغلبة للأصوات المجهورة (الباء، الجيم، العين، اللام، النون) عند الحديث عن صفات الصبر ، وكأنّها ترسم بنغمتها حكاية صوتية لرحلة شاقة للصابرين مع الصبر • - نوع ابن الرومي في الموسيقى الداخلية مما أحدث تكافؤا صوتيا دلاليّا من خلال تتوع المحسنات البديعيّة، فزخرت القصيدة بضروب مختلفة من فنون البديع من جناس وطباق تقسيم وتصدير، فأضفت فنون البديع سمة جمالية إيقاعية كثفت عنها النغمة الداخلية من خلال الكلمات، وكان لها تأثيرها الواضح في بلاغة الخطاب وإيصال مضمونه. - جاء بناء النصّ قائم على مجموعة من الظواهر

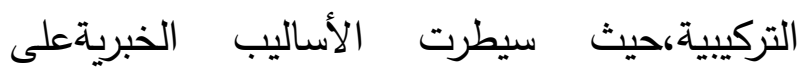
القصيدة؛ وذلك لأنّ محورها الحكمة التي تتطلّب تأكيدًا لمضمونها،كما نوّع الشاعر بين الجمل الفعلية والجمل الإسمية، فكانت الجمل الفعلية عند الحديث عن المواقف والتجدّد والاستمرارية، والاسمية عند التأكيد والثبات. الظواهر التركيبية دور بارز في بناء القصيدة . - تمثّل لفظة (الصبر) القالب الأساسي للقصيدة، ثمّتأتي المفردات المجاورة لوصف الصبر وأحواله موزعة في نسق النص ،فقدمت هذه الكلمات من خلال ما تحمله من دلالات معنى دقيق مستقصي وهي خاصية أسلوب ابن الرومي في أدبه. - تعد نظرية الحقول الدلالية من أهم الظواهر الأسلوبية التي تُعرّف بعلاقاته الداخلية، فقد تضمنت القصيدة حقلين دلالين حقل الصبر، وحقل الجزع فمن خلال هذا التقابل يجعل الخطاب الدلالي قارئ النص ذا قرار تصنعه المفردات بما تحمله من إيحاء ات. -اعتمد البناء الدلاليّ في هذه القصيدة على ظاهرة التقابل الدلاليّ، فجاء هذا النمط التركيبيّ متناسبًا مع أسلوب الخطاب المتّبع في هذه القصيدة في مخاطبة النفس. - تتّصف البنية الإيقاعيّة عند ابن الروميّ بإيقاعها الخاصٌ الذي يوظّف عناصر الموسيقى الداخليّة و الخارجيّة، كجزء من دلالة النصّ،فالموسيقى الخارجيّة متمثّلة في الوزن والقافية جاءت متناسبة مع الدلالات السياقيّة لقصيدة (أرى الصبر محمودا) - - جاءت القصيدة على البحر الطويلفن خلال هذا الوزن الشعريّ بتفعيلاته القويّة تحقّق للقصيدة التعبير عن معنى الصبر وما يحتاجه هذا المعنى من اتساعٍ 


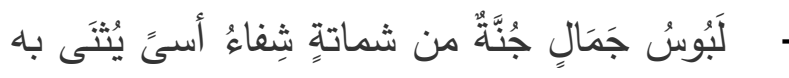

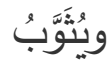

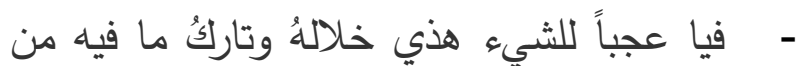

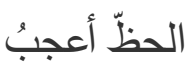
وقد يَتظنَّى الناشُ أنّ أَساهُهُ وصبرَهْمُ فيهم طِباعُ

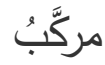

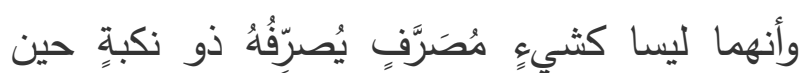
يُنكبُ فإن شاء أن يأستى أطاع له الأسى وإن شاء صبراً جاءهُ الصبرُ يُجلَبُ كُبْ ولكن ضروريان كالثيء يُبتلى به المريُ مَتْلوباً

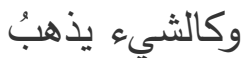
وليسا كما ظنوهما بل كلاهما لكل لبيٍٍ مستطاعٌ مُسبَّبُ كمبان يُصرِّفه المختارُ منا فتارةً يُرادُ فيأتي أو يُنادُ فيذْْبُ

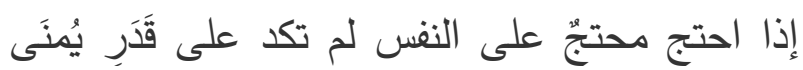
لها تتعتبُّ وساعَدَها الصبرُ الجميلُ فأقبلتُ إليها له طوعاً

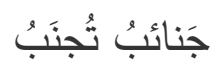
وإنْ هو منَّاها الأباطيل لم تزل تُقاتل بالتَبٍْ القضاءَ

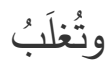
فَتَّحي جزوعاً إن أصابتُ مصيبةٌ وتُمسي هلوعاً

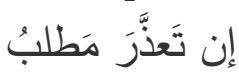

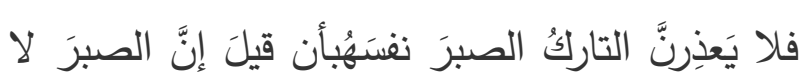

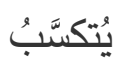

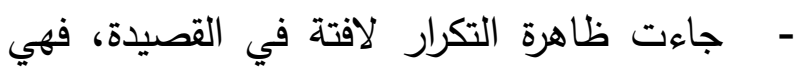
بمثابة متنف لما يشعر به الثاعر وترجمان لحالته

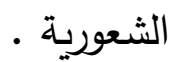
- - قلة الصور في القصيدة؛ لأنها تندرج تحت شعر الحكمة والتي من خصائصه قلّة الصور و إظهار - الحقائق والوقائع من

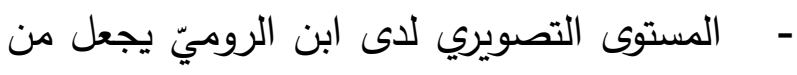
الصبر صورة ترتبط بالنفس، فقرّب صور المعنويات، الكئ

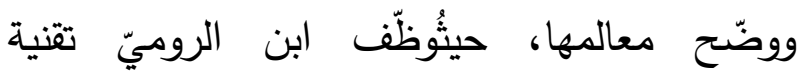
التصوير بالتثخيص، فأنطق الجماد وبكَّ فيه الحياة، فنقل حكته إلى المتلقي بشكل صورة جماليّة مؤثرةمنبعثة من نفس متألمة ترجمت شخصية ابن الرومي ومرارة ما عانه من مكاره.

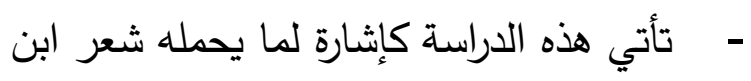

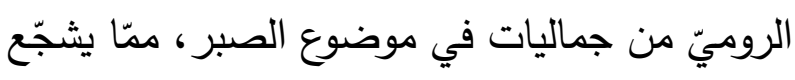
على دراسة أوسع للصبريّات في شعر ابن الروميّ. نص الدراسة

- - أرى الصبر محموداً وعنه مذاهبّ فكيف إذا ما

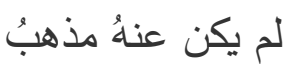
- - هناكَ يَجِقُ الصبرُ والصبرُ واجبُوما كان منهـ

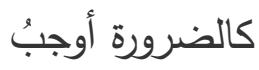

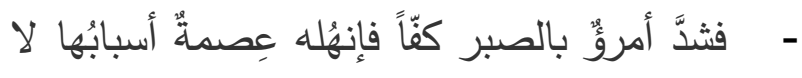

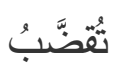

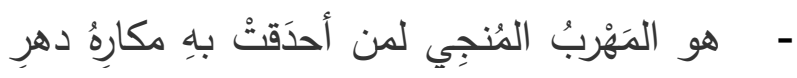

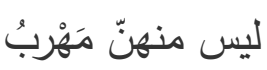
- ـ أَعُدُ خِلالاً فيه ليس لعاقل من الناس إن أُنصفنَ 
- شلبي، سعد إسماعيل ،الأصول الفنية للشعر الجاهلي ، مكتبة غريب ، ط طب، د.ت - الشوكاني، محمد بن علي، فتح القدير الجامع

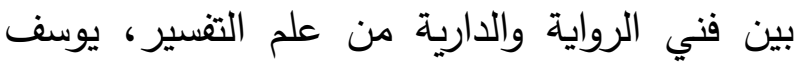

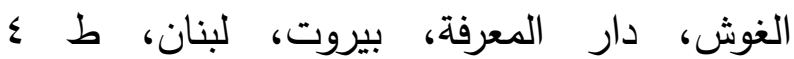

$$
\text { . }
$$

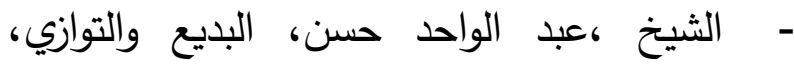

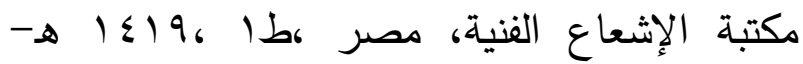
. $) 999$

- صبح، علي، البناء الفنيل لصورة الأدبية في

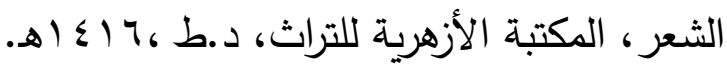

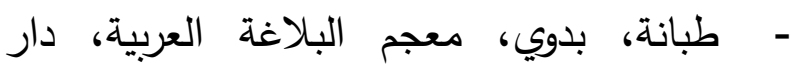

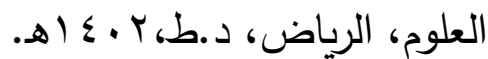

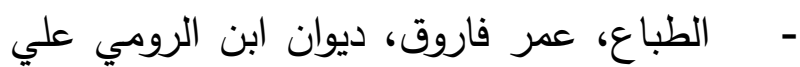

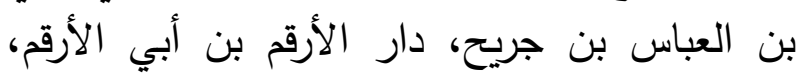

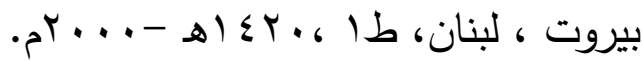
وصناعتها، دار جامعة الخرطوم للنشر، السودان . 9991 ، 9 b6

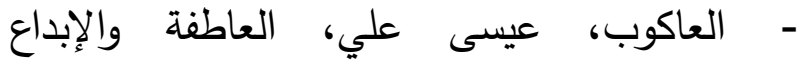
الشعري، دار الفكر ، دمشق ، طا، سب ع اهـ.

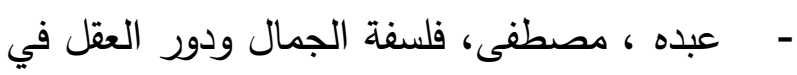

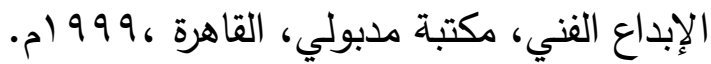
-

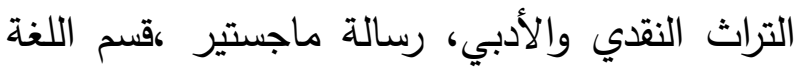

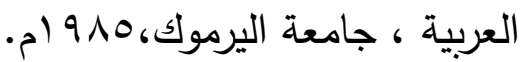

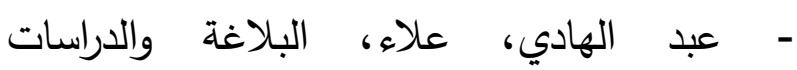
البلاغية، أعمال المؤتمر الدولي الرابع للنقد الأدبي

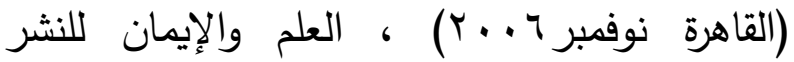

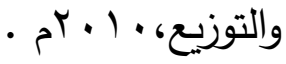

\section{فهرس المصادر والمراجح:}

- أبو العدوس ، يوسف ،الاستعارة في النقد

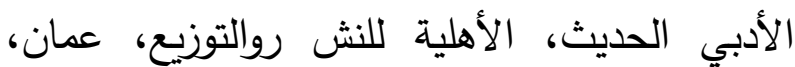
. 199V (19) - ابن خلكان، أحمد بن محمد، وفيات الأعيان وإنباء أبناء الزمان، حققه: إحسان عباس، دار ارن

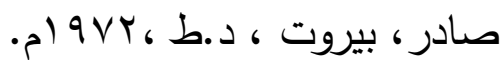

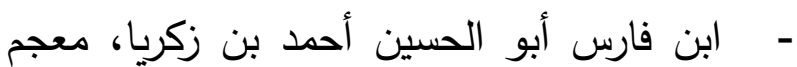

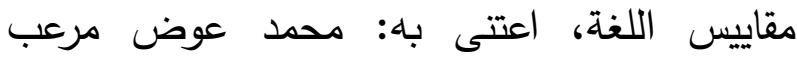
وفاطمة أصلان، دار إحياء التراث العربي، بيروت ، معايهن، طا، - البرقوقي، عبدالرحمن، شرح ديوان المتنبي،

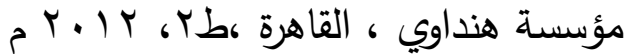
- مسين، طه، منحديث الثعر والنثر، مؤسسة هنداوي للتعليم والثقافة، القاهرة ،د.ط ، ب ا • بم.

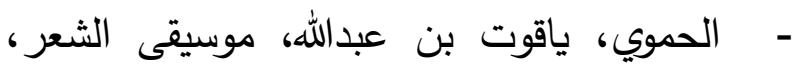
دار الفكر ، بيروت ،د.ط ،د.ت.

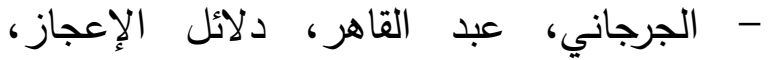
تصحيح: محمد السيد رشيد، مكتبة محمد علي،

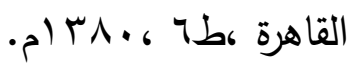
- الجرجاني، علي بن محمد بن علي الثريف، التعريفات، تحقيق: محمد صديق المنشاوي،دار الفضيلة للنشر والتوزيع، القاهرة،د.ط،د.ت. - الجيار، شريف سعد، شعر إبراهيم ناجيدراسة

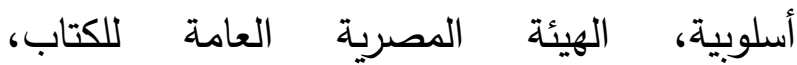

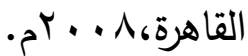
- دريش ،أحمد ،دراسة الأسلوب بين المهاب المعاصر

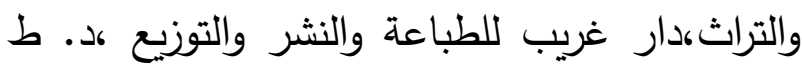
ك6.ت.
- سلطان ، منير ،البديع تأصيل وتجديد ، منشأة

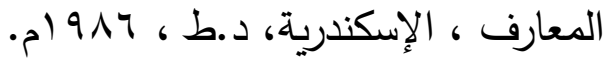


- عتيق، عبدالعزيز، علم العروض والقافية، دار مطلوب ،أحمد، معجم النقد العببي القديم، دار

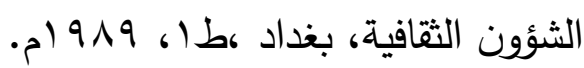

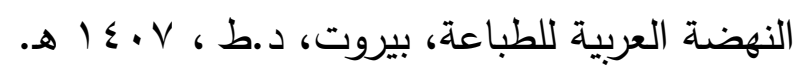

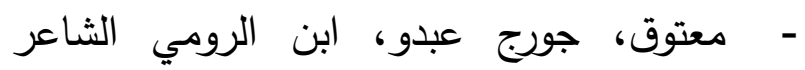

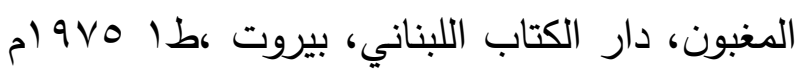

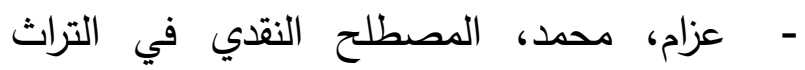

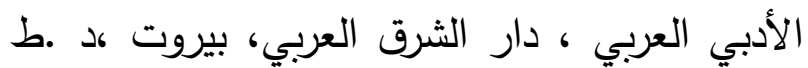

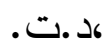

- الملائكة، نازك ، قضايا الثعر المعاصر، دار

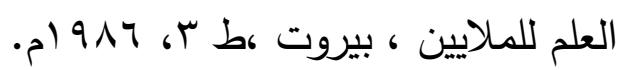

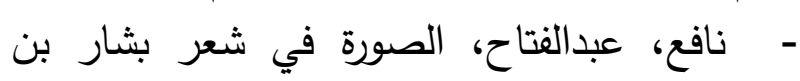

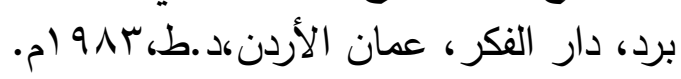

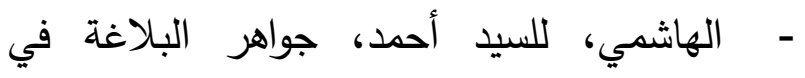

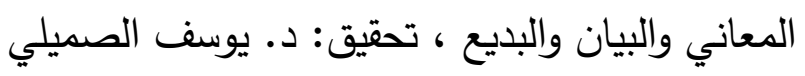

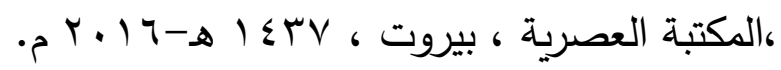

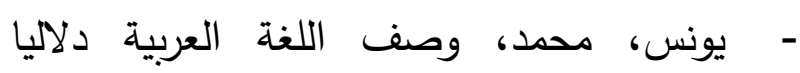

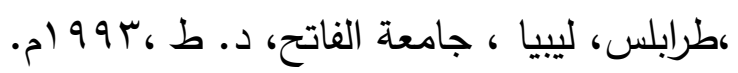

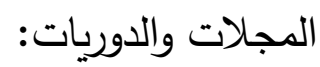
- جمالية فلسفة الدهاتة في الثعر العربي

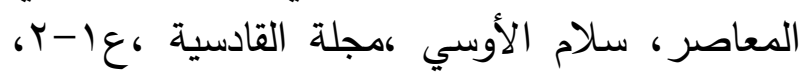
حزيران 0 . . بم. - ق قراءة في قصيدة من الثعر المغربي القديم

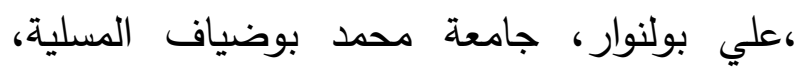
الجزائر ، مجلة التراث العربي ، 1 • 1.

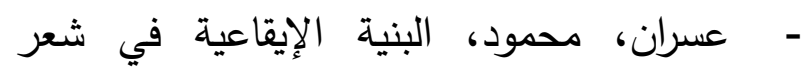

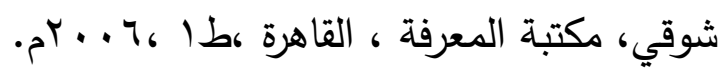

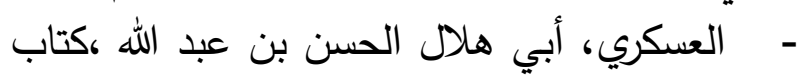

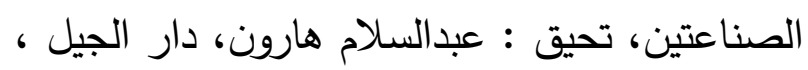

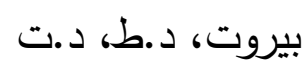

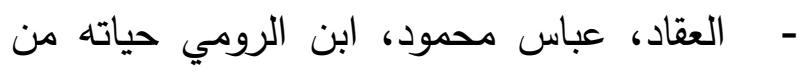

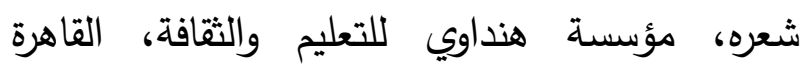

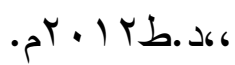
- فاعور، علي حسن، ديوان زهير بن أبي سلمى،

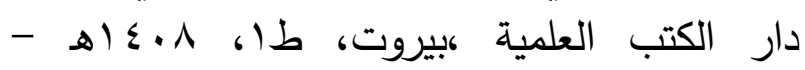
.م 911

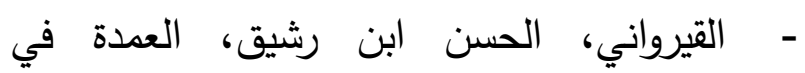

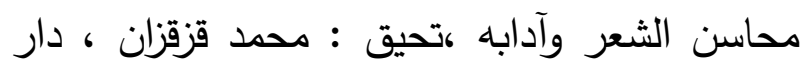

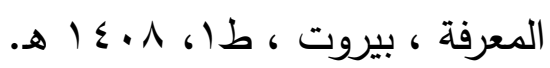

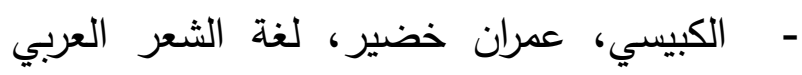

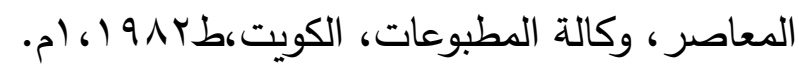

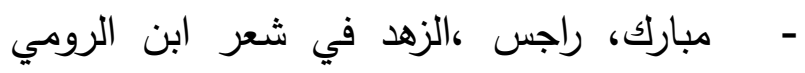

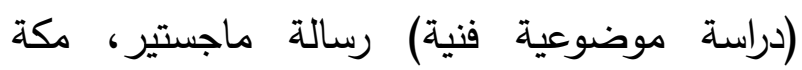
المكرمة ، المملكة العربية السعودية. 


\title{
Aesthetics of Patience in Ibn Alroomi's Poem "As I see it, Patience is Likable" An Analytical Study of Semantics and Stylistics
}

\author{
Noor owaidhaalrefaei \\ University of Jeddah
}

\begin{abstract}
Ibn AlRoomi's poem "As I see it, Patience is likable" in order to reveal the sources of spiritual beauty implemented in the verses from the semantic level as well as the sources of artistic beauty and its creative characteristics in the constructive stylistic level of the poem.

The study is divided into two fields: the sematic and stylistic aesthetics. In the semantic level,various meanings are shown through the pairings which Ibn AlRoomi built on his intended meanings taking such semantic implications into varied stylistic components used to empower the text like:

The implications of words and structures in which he relies first on the accuracy of word choice to suit the context of self-talk and through repetition resulted from the smallest component in the text.

In addition, he applies parallelism in the semantic fields to enrich the text and add life to it.

As for the vocal implication, it is represented through the outer music (rhythm and rhyme) and the inner music produced from the various sounds of the letters (Hams and Jahr) as well as using the vocal and spiritual rhetoric.

The second field of the research concentrates on the stylistic beauty tackling the affirmative structural styles, the composed ones, and repetition then the descriptive styles which revealed the artistic images in the poem.

Key Words: Aesthetics, Patience, Ibn AlRoomi, Implications, Styles
\end{abstract}

